\title{
How Do Multiscale Interactions Affect Extreme Precipitation in Eastern Central Asia?
}

\author{
Qianrong Ma, ${ }^{\mathrm{a}}$ Jie Zhang, ${ }^{\mathrm{a}}$ Yujun Ma, ${ }^{\mathrm{b}}$ Asaminew Teshome Game, ${ }^{\mathrm{a}, \mathrm{c}}$ Zhimeng Chen, ${ }^{\mathrm{a}}$ \\ Yi CHANG, ${ }^{\mathrm{d}}$ AND MEICHEN LiU ${ }^{\mathrm{a}}$ \\ ${ }^{\text {a }}$ Key Laboratory of Meteorological Disaster, Ministry of Education (KLME)/Joint International Research Laboratory of \\ Climate and Environment Change (ILCEC)/Collaborative Innovation Center on Forecast and Evaluation of Meteorological \\ Disasters (CIC-FEMD), Nanjing University of Information Science and Technology, Nanjing, China \\ ${ }^{\mathrm{b}}$ Key Laboratory of Mechanics on Disaster and Environment in Western China Ministry of Education, Lanzhou University, \\ Lanzhou, China \\ ${ }^{\mathrm{c}}$ National Meteorological Agency of Ethiopia, Addis Ababa, Ethiopia \\ ${ }^{\mathrm{d}}$ Key Laboratory for Cloud Physics, China Meteorological Administration, Beijing, China
}

(Manuscript received 9 October 2020, in final form 14 May 2021)

\begin{abstract}
The variability of extreme precipitation in eastern central Asia (ECA) during summer (June-August) and its corresponding mechanisms were investigated from a multiscale synergy perspective. Extreme precipitation in ECA displayed a quasi-monopole increasing pattern with abrupt change since 2000/01, which was likely dominated by increased high-latitude North Atlantic SST anomalies as shown by diagnosed and numerical experiment results. Increased SST via adjusting the quasi-stationary wave train that related to the negative North Atlantic Oscillation (NAO) and the east Atlantic/western Russia (EA/WR) pattern guided the cyclonic anomaly in central Asia, deepened the Lake Balkhash trough, and enhanced the moisture convergence in ECA. These anomalies also exhibited interdecadal enhancement after 2000. On the synoptic scale, two synoptic transient wave trains correlated with extreme precipitation in ECA by amplifying the amplitude of the quasi-stationary waves and guiding transient eddies in ECA. The induced transient eddies and deepened Lake Balkhash trough strengthened positive meridional vorticity advection and local positive vorticity, which promoted ascending motions, and guided the southerly warm moisture in ECA especially after 2000. Meanwhile, additional mesoscale vortices were stimulated and strengthened near the Tianshan Mountain in front of the wave trough, which, together with the enhanced meridional circulation, further increased extreme precipitation in ECA.
\end{abstract}

KEYWORDS: Atmosphere-ocean interaction; Atmospheric circulation; Extreme events; Precipitation

\section{Introduction}

Since the 1990s, extreme precipitation has been increasing in frequency and intensity, which generally triggers serious geological catastrophes including floods, mudslides, and landslides (Buri et al. 2015; Knapp et al. 2008; Revadekar and Preethi 2011; Wang et al. 2016). Moreover, its impacts on human health, agriculture, and social economy are also severe (Du et al. 2013; Park et al. 2009; Wang et al. 2015; Wu et al. 2018). Recently, extreme precipitation has attracted unremitting attention from the scientific community and public (Alexander et al. 2006; Donat et al. 2016a,b), and the IPCC Fifth Assessment Report (IPCC 2013) reported that extreme precipitation has increased across several regions such as China, central Asia, northeast Australia, North America, and southwest Europe (Chen and Zhai 2013; Evans and Boyer-Souchet 2012; Jiang et al. 2015; Kunkel 2003; Madsen et al. 2014; Prein et al. 2016; Queralt et al. 2009). Future projections suggest that extreme precipitation is likely to sequentially increase (Chen and Sun 2017; Orlowsky and Seneviratne 2012). Remarkably, precipitation and extreme precipitation have increased in several arid and semiarid regions (Donat et al. 2016b; Fumière et al. 2019; Hu et al. 2016b; Zhang et al. 2017). For these regions, extreme precipitation is vital for water resources and catastrophic to fragile ecosystems (Deng et al. 2014; Omondi et al.

Corresponding author: Jie Zhang, zhangj@nuist.edu.cn
2014; Xue et al. 2017). Therefore, the aforementioned studies encourage us to investigate the variation and formation mechanisms of extreme precipitation in arid and semiarid regions.

Central Asia (CA) acts as a key connecting region of the Silk Road Economic Belt extending from Asia to Europe and features one of the largest semiarid to arid regions worldwide (Chen et al. 2019; Wang et al. 2020). In CA, water is a scarce and pivotal resource for socioeconomic development, which is vulnerable to extreme precipitation (Bothe et al. 2011; Hu et al. 2017, 2014; Huang et al. 2014; Lioubimtseva and Henebry 2009; Malsy et al. 2015; Zhang et al. 2017; M. Zhang et al. 2020). With a population of 78 million, CA is located in the hinterland of the Eurasian continent, away from the ocean (Fig. 1), and comprises five Asian republics (Kazakhstan, Kyrgyzstan, Tajikistan, Turkmenistan, and Uzbekistan) and part of northwest China (the Xinjiang Uygur Autonomous Region of China) (Hu et al. 2016a). It has scarce precipitation and significant evaporation, and recent studies showed that its climate is highly sensitive to global climate change (Hu et al. 2016b; Jiang et al. 2020; Li et al. 2015; Yin et al. 2014). The surface temperature increase in $\mathrm{CA}\left(0.39^{\circ} \mathrm{C}\right.$ decade $^{-1}$ during $1979-$ 2011) exceeds the average change rate over the Northern Hemisphere. Furthermore, annual precipitation and extreme precipitation showed increasing trends in recent decades (Chen et al. 2009; Hu et al. 2016b, 2014; Jiang et al. 2020; Zhang et al. 2017; M. Zhang et al. 2019), especially in the Xinjiang province (Deng et al. 2014; Huang et al. 2015). With relatively 


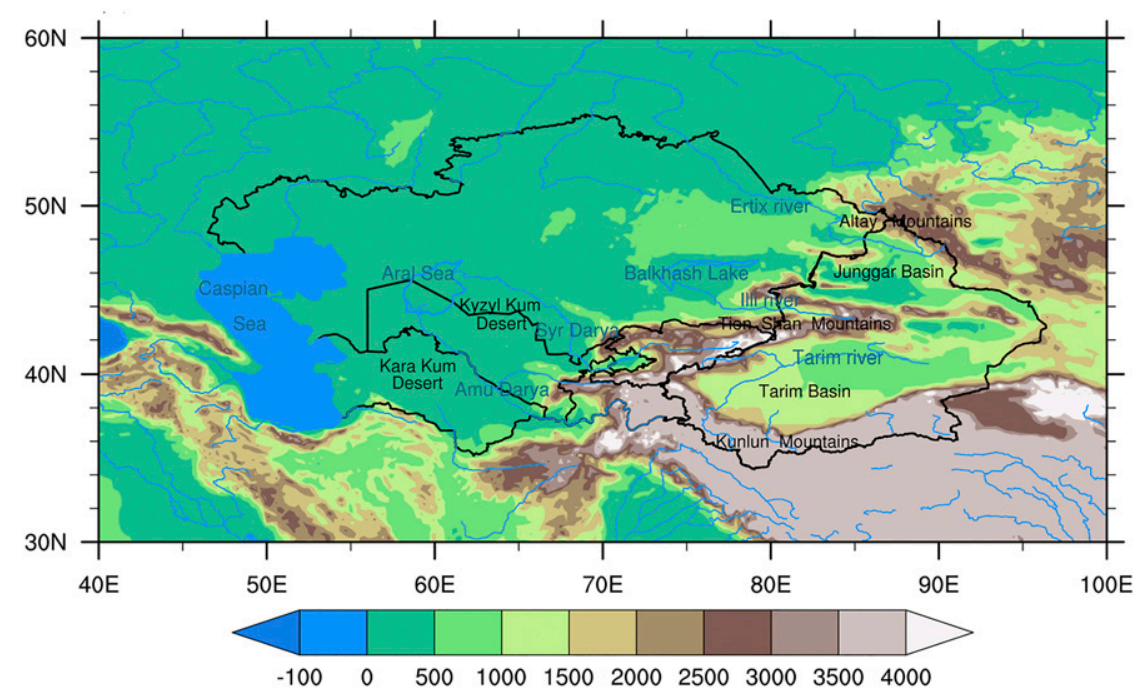

FIG. 1. Topography of central Asia (CA) and major land features. The black solid line delineates the region of $\mathrm{CA}$, and shading indicates elevation $(\mathrm{m})$.

infertile soil, fragile ecosystems, and typical continental climate, $\mathrm{CA}$ is susceptible and vulnerable to unexpected extreme precipitation changes (Jiang et al. 2020; Mathis et al. 2014; Varis 2014; J. Zhang et al. 2019). Nevertheless, studies about the long-term spatiotemporal variations and relevant physical mechanisms of extreme precipitation in CA are far from enough, and additional efforts are needed as extreme precipitation is challenging for water resource management and natural hazard prevention.

Most previous research reflects that the anomalous atmospheric circulation and sea surface temperature (SST) anomalies are responsible for extreme events. The multiple key and stable anomalous atmospheric circulations are likely to induce or enhance extreme precipitation events via their slower movement and longer lifespan (Chen and Zhai 2014; Fujinami and Yasunari 2009; Hu et al. 2015; Huang et al. 2015; Liu et al. 2015). Large-scale atmospheric circulation patterns and relevant teleconnections, such as the east Atlantic/western Russia (EA/WR), the North Atlantic Oscillation (NAO), the east Atlantic (EA), and the Silk Road Pattern (SRP) over Eurasia are very active and usually associated with extreme precipitation (Bothe et al. 2011; Miao et al. 2019; Yang 2007; J. Zhang et al. 2020). Particularly, EA/WR dominates two main circulation anomalies over western Europe and the Caspian Sea, and its impacts are strong enough to extend across Europe to Siberia and midlatitude East Asia (Krichak et al. 2014). Bothe et al. (2011) showed that the EA/WR pattern significantly influences the regional precipitation in CA. Different NAO phases led specific synoptic situations that relate to severe weather (Wang et al. 2013). In addition, the NAO can influence Asian climate anomalies by the EA and SRP pattern ( $\mathrm{Li}$ et al. 2019; J. Zhang et al. 2020). Besides, CA is regarded as the core region for the "westerlies-dominated climatic regime" and it is necessary to understand the changes in response of extreme precipitation to westerly variations (Chen et al. 2019; Huang et al. 2013). Schiemann et al. (2008) found that the westerly jet usually combines with synoptic disturbances, leading to precipitation anomalies in CA. Furthermore, the duration and intensity of synoptic circulation patterns are also responsible for extreme precipitation events (Bueh et al. 2011; Ding and Li 2017; Huang et al. 2018; Wen et al. 2009). Chen et al. (2013) reported that two synoptic-scale transient waves in mid- and high-latitude Eurasia provide an important condition for the occurrence of extreme precipitation in China. As the main purpose of this study is to explore the multiscale synergy influences on the summer extreme precipitation variations in CA, the synoptic time scale circulation anomalies also need to be considered.

Considering the interrelationship between the atmosphere and oceans, Atlantic SST anomalies act as one of the most important mechanisms for precipitation and extreme precipitation in Eurasia (Bothe et al. 2011; Liu et al. 2017; Wolff et al. 2017; M. Zhang et al. 2020). Lu et al. (2020) found that SST anomalies in the North Atlantic can stimulate two wave trains over the middle and high latitudes in Eurasia and produce precipitation anomalies over central and northeastern Asia. Besides, North Atlantic SST anomalies are closely related to the EA/WR, SRP, and NAO, which further regulate the westerly jet and upper-troposphere convergence zone and further lead to precipitation anomalies (Bothe et al. 2011; Lim 2015; Wang et al. 2013; J. Zhang et al. 2020). Previous studies also indicate that the loss of sea ice over the Barents Sea is likely to influence extreme events over North China via teleconnection patterns that pass by CA (Fan et al. 2018; Li et al. 2018). Additionally, Huang et al. (2015) suggested that SST anomalies in the Indian Ocean can strengthen warm moisture transport and regulate the precipitation episodes in CA.

Overall, the semiarid and arid CA tends to be wet and experience precipitation increases in recent decades (F. Chen et al. 2008; Peng and Zhou 2017). Zhang et al. (2017) demonstrated that most extreme precipitation indices in CA showed increasing trends before 2005. However, previous studies mainly focused on the annual and winter extreme precipitation, and few investigations focused on recent variations and 
physical processes of summer extreme precipitation in CA. Improving our understanding of these situations can enable accurate predictability of extreme precipitation in CA. Thus, this study mainly focused on unraveling these questions. The rest of this paper is organized as follows: data and analysis methods are described in section 2; in section 3 , first, the spatiotemporal characteristics and variation of summer extreme precipitation are discussed, and then the physical mechanisms are discussed from a multiscale synergy perspective. Finally, conclusions and discussion are provided in section 4 .

\section{Data and method}

\section{a. Data}

The daily precipitation dataset was obtained from National Oceanic and Atmosphere Administration's (NOAA) Climate Prediction Center (CPC) Unified Precipitation Project, which specializes in constructing global high-quality and consistent land precipitation products (Ma et al. 2020). First, the daily precipitation dataset is obtained from dense gauge precipitation observation, which is collected from the Climate Anomaly Monitoring System, Global Telecommunication System, National Weather Service (NWS), River Forecast Centers (RFC), and Hydrologic Automated Data System (HADS) (Xie et al. 2007; Cui et al. 2017). Then, the CPC daily precipitation dataset is interpolated via the optimal interpolation objective analysis technique and quality control (M. Chen et al. 2008; Silva et al. 2011). Precipitation estimates from reanalysis datasets showed similar distribution and trends with CPC, but large regional and seasonal overestimations exist (Cui et al. 2017). In general, CPC daily precipitation data are widely used in climate research (Bosilovich 2013; Prakash et al. 2015). Ma et al. (2020) found that CPC daily precipitation performs well in CA via comparing with the Global Precipitation Climatology Project (GPCP) and the TRMM 3B42-V7 datasets. In this study, the gridded $0.5^{\circ} \times 0.5^{\circ}$ daily CPC precipitation data were used as the primary validation data to calculate extreme precipitation.

The daily and monthly reanalysis data were obtained from the European Centre for Medium-Range Weather Forecasts (ECMWF) interim reanalysis dataset with a horizontal resolution of $0.75^{\circ} \times 0.75^{\circ}$ (Dee et al. 2011). Variables mainly included the geopotential height, zonal and meridional wind, vertical velocity, relative humidity, specific humidity, and relative vorticity during the period from 1979 to 2018. The hourly ERA5 is a latest generation global reanalysis dataset developed by ECMWF (Sun et al. 2020), with horizontal resolution of $30 \mathrm{~km}$, which is higher than that of ERA-Interim $(79 \mathrm{~km})$. ERA5 further improved the reanalysis data quality by modifying the data assimilation system and improving the physical model (Hersbach et al. 2020). The hourly ERA5 dataset with spatial resolution of $0.25^{\circ} \times 0.25^{\circ}$ was also used. Variables mainly included the geopotential height, zonal and meridional wind, vertical velocity, and relative vorticity.

The Northern Hemisphere EA/WR and NAO index were accessed from the CPC (https://www.cpc.ncep.noaa.gov/data/ teledoc/telecontents.shtml). Additionally, the monthly mean SST data were obtained from the Hadley Centre Sea Ice and Sea
Surface Temperature dataset (HadISST) with horizontal resolution of $1^{\circ} \times 1^{\circ}$ during 1979-2018 (Rayner et al. 2003).

The Fengyun-2G $(F Y-2 G)$ stationary satellite provides five bands of measurements, including one visible band $(0.55-0.75 \mathrm{~mm})$ at $1.25-\mathrm{km}$ resolution, and one middle-infrared $(3.5-4.0 \mathrm{~mm})$, two thermal infrared (10.3-11.3 and 11.5-12.5 mm), and one water vapor band $(6.3-7.6 \mathrm{~mm})$ at a $5-\mathrm{km}$ resolution (J. Zhang et al. 2019). FY-2G data have been developed for weather monitoring and predictions. The hourly equivalent blackbody temperature (TBB) can well reflect synoptic-scale cloud developments and activity tracks and was used in this study.

\section{b. Method}

The empirical orthogonal function (EOF; Lorenz 1956; Wilks 2006) analysis was applied to obtain the leading mode of summer extreme precipitation in eastern CA during 1979 to 2018 and its statistical significance was assessed by employing North's test (North et al. 1982). Linear regression and Pearson correlation were used to explore the meteorological factors influence on extreme precipitation. The statistical significance was evaluated using the Student's $t$ test. Subsequently, the Mann-Kendall and the moving $t$ test (MTT) used to detect changepoint (Wu and Huang 2015).

In contrast, the vertical integrated water vapor transport flux (WVT) was calculated from surface to $300 \mathrm{hPa}$ using the method proposed by Trenberth (1991). To investigate the atmospheric teleconnection responsible to the variability of extreme precipitation, several climate dynamic methods employed. First, the wave activity flux (WAF) was calculated as proposed by Takaya and Nakamura (2001), diagnosing the Rossby wave train energy dispersion characteristics:

$$
W=\frac{1}{2|\bar{U}|}\left[\begin{array}{l}
\bar{u}\left(\psi_{x}^{\prime 2}-\psi^{\prime} \psi_{x x}\right)+\bar{v}\left(\psi_{x} \psi_{y}^{\prime}-\psi^{\prime} \psi_{x y}\right) \\
\bar{u}\left(\psi_{x}^{\prime} \psi_{y}^{\prime}-\psi^{\prime} \psi_{x x}^{\prime}\right)+\bar{v}\left(\psi_{y}^{\prime 2}-\psi^{\prime} \psi_{y y}^{\prime}\right)
\end{array}\right],
$$

where $\psi$ and $\mathbf{U}=(u, v)$ represent the streamfunction and horizontal wind, respectively. The climatological mean and anomalies are denoted by an overbar and prime, and $W$ represents WAFs.

To validate the synoptic-scale transient waves, $u^{\prime}$ and $v^{\prime}$ were obtained by the 2.5-6-day bandpass filtering technique at $300 \mathrm{hPa}$ because the transient wave activity is mainly concentrated in the upper troposphere (Chen et al. 2012; Murakami 1979). The average intensity of transient waves is represented by $\overline{v^{\prime 2}}$ and the transient disturbance kinetic energy $K_{t}$ is defined as $K_{t}=\overline{\left(u^{\prime 2}+v^{\prime 2}\right)} / 2$. In addition, Wu (2001) showed that the development of short-time local positive vorticity can affect long-time atmospheric circulation through the $\beta$ effect. According to the vorticity equation produced by Wu (2001):

$$
\frac{d \xi_{z}}{d t}+\beta v+\left(f+\xi_{z}\right) \cdot \nabla \mathbf{V}=\rho \frac{d}{d t}\left[\frac{P}{\theta_{Z}}-C_{D}\right],
$$

where $\xi_{z}$ is relative vorticity, $f$ is the Coriolis parameter, $\theta_{z}$ is vertical gradient of potential temperature, $\beta$ is the Rossby parameter, and $C_{D}=\alpha \nabla \times \mathbf{V} \cdot\left(\nabla_{h} \theta / \theta_{Z}\right)$. The daily and hourly vorticity advection defined as $\left(f+\xi_{z}\right) \cdot \nabla \mathbf{V}$ was employed to 

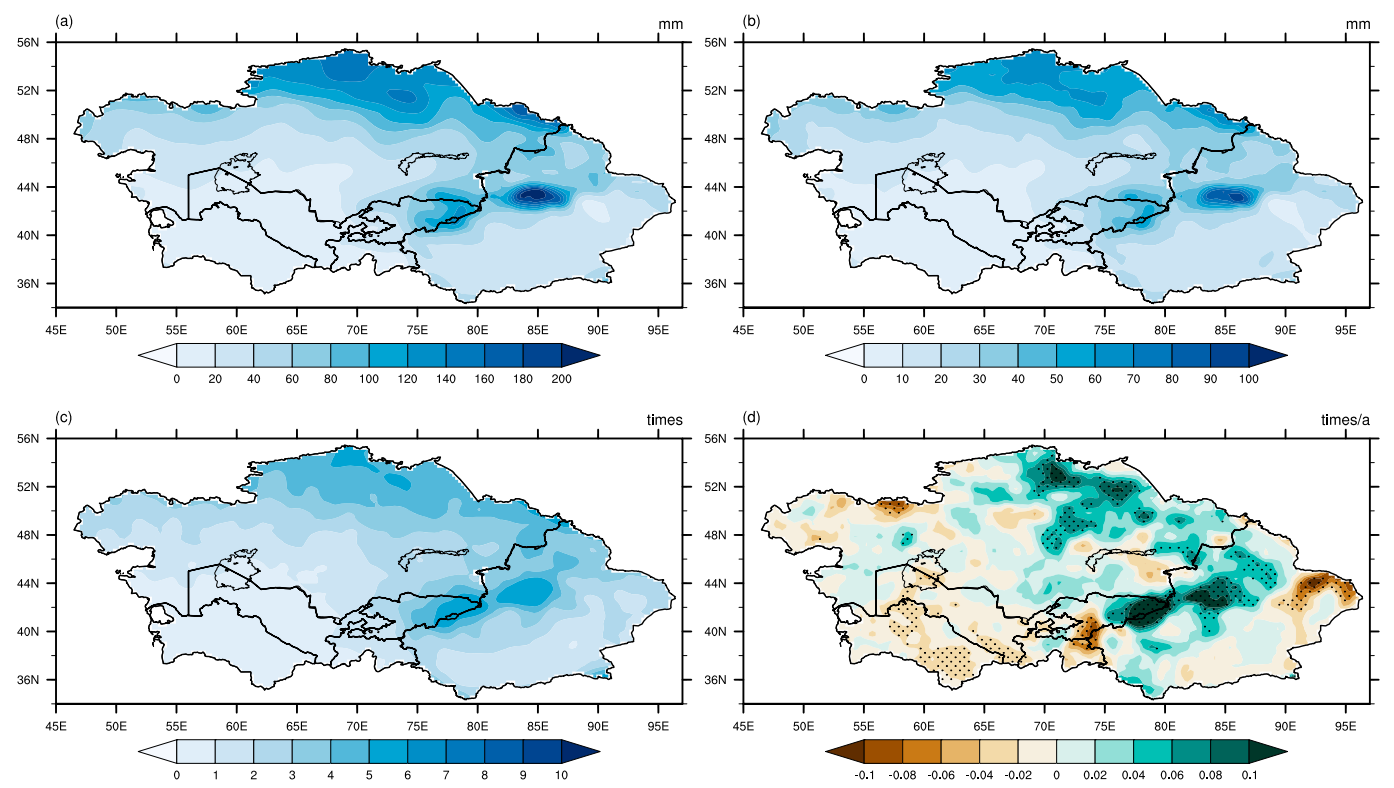

FIG. 2. Spatial distribution of (a) summer total precipitation ( $\mathrm{mm}$ ), (b) summer extreme precipitation (R90p; $\mathrm{mm}$ ), (c) frequency of extreme precipitation (R90f; events), and (d) linear trend of R90f (events per year) during 1979-2018 in CA. Dots in (d) denote the $95 \%$ confidence level.

denote the influences of synoptic-scale systems on extreme precipitation (Carroll 2006).

\section{c. Definition of extreme precipitation}

Extreme precipitation indices are provided by the World Meteorological Organization (WMO) Expert Team on Climate Change Detection and Indices (ETCCDI; http:// etccdi.pacificclimate.org/list_27_indices.shtml) and widely used in extreme weather and climate research (Klein Tank et al. 2006). This study selected the value of $90 \%$ quantile of wet days in summer (June to August) as the extreme precipitation threshold in CA during 1979-2018.

In semiarid and arid CA, summer total precipitation peaks occur in the Tianshan Mountain ranges and northern Kazakhstan (Fig. 2a; Hu et al. 2017; Wolff et al. 2017). Extreme precipitation (R90p) and the frequency of extreme precipitation (R90f) exhibited similar spatial distribution characteristics with summer total precipitation (Figs. 2b,c). Besides, in Fig. 2d R90f showed a significant increase in the most eastern CA especially in northeastern Kazakhstan and the Tianshan Mountains (Huang et al. 2013; Ma et al. 2020; Zhang et al. 2012). Thus, the following study mainly focused on extreme precipitation changes in eastern central Asia (ECA; i.e., eastward of $65^{\circ} \mathrm{E}$ across CA).

\section{d. Model}

To clarify our conclusions for relationships between SST anomalies and extreme precipitation in ECA, the Community Atmosphere Model version 5.1 (CAM5.1) is employed to conduct two experiments. These simulations have a horizontal resolution of $1.9^{\circ}$ latitude $\times 2.5^{\circ}$ longitude and 37 vertical layers (Garcia et al. 2007), which include a control and sensitivity experiment. The control experiment is designed as the climatic monthly SST during 1981-2010
(Chen and Zhang 2020; Hurrell et al. 2013). The sensitivity experiment SST condition are specified in section 3b(2). Both experiments are run for 50 model years and the output of the last 40 model years are analyzed.

\section{Results}

\section{a. The leading mode of summer extreme precipitation in ECA}

The first EOF mode of R90f explained $20.02 \%$ of the total variance and was statistically significant and independent according to the North's test criteria (North et al. 1982). Moreover, its spatial pattern characterized by positive changes over most regions, with a maximum over northern Kazakhstan and the Tianshan Mountains, and suggested a quasi-monopole pattern (Fig. 3a). The time series of PC1 and standardized regional averaged R90p in ECA were shown in Fig. 3b. The correlation coefficient between $\mathrm{PC} 1$ and the time series of standardized regional averaged R90p in ECA reached 0.75 (exceeding 99\% confidence level), which indicated that the first EOF mode can typically represent extreme precipitation changes in ECA during 1979-2018. Besides, the Mann-Kendall test (Fig. 3c) indicates that $\mathrm{PC} 1$ experienced a significant interdecadal increasing since 2000/01 (exceeding the $95 \%$ confidence level).

\section{b. Large-scale atmospheric circulation and SST anomalies}

\section{1) LARGE-SCALE ATMOSPHERIC CIRCULATION ANOMALIES}

The regressed wind field at $200 \mathrm{hPa}$ and geopotential height at $500 \mathrm{hPa}$ against $\mathrm{PC} 1$ during 1979-2018 were presented in Figs. $4 \mathrm{a}$ and $4 \mathrm{~b}$, respectively. A significant quasi-stationary wave train was captured over the mid-high latitudes $\left(30^{\circ}-60^{\circ} \mathrm{N}\right)$ 

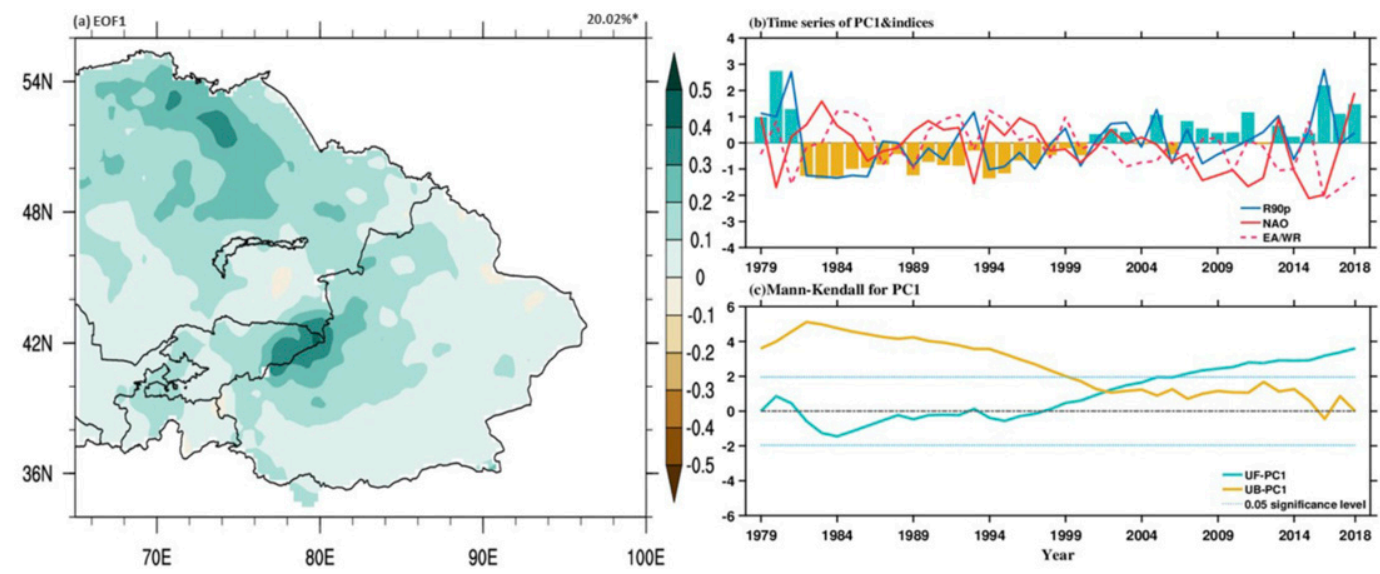

FIG. 3. (a) The spatial pattern (shading; $\mathrm{mm}$ ) and (b) corresponding principal component (PC) time series (bar diagram) of the first EOF mode of R90f in ECA. The number and asterisk in (a) represent the total variance and statistical significance and independence from other modes according to North's test, respectively. The blue solid line, red solid line, and red dashed line in (b) denote the time series of standardized regional averaged extreme precipitation in the ECA, NAO, and EA/WR index, respectively. (c) Mann-Kendall test of PC1. UF and UB (red and blue lines, respectively) indicate the time series of the positive and inverse sequence calculation, and the dashed lines represented the $95 \%$ confidence level.

in Eurasia, which was characterized by anomalous cyclones centered in Northern Ireland, northwest Russia, and CA, and anticyclones over the mid- to low-latitude North Atlantic, western Eurasia, and the east of Xinjiang. The geopotential height at $500 \mathrm{hPa}$ from $80^{\circ} \mathrm{N}$ to the North Atlantic was characterized by positive anomalies in northern Iceland and mid-lowlatitude North Atlantic, respectively, and negative geopotential height centered in the Hebrides, which exhibited a negative NAO pattern. The correlation coefficient between PC1 and the NAO index (in Fig. 3b) was -0.41 (above $99 \%$ confidence interval). Meanwhile, the positive geopotential height was characterized in west Eurasia by corresponding to a negative
EA/WR pattern and the correlation coefficient between PC1 and the EA/WR index (in Fig. 3b) was -0.52 (above $99 \%$ confidence interval). Moreover, increased extreme precipitation in ECA was influenced by anomalous moisture transports from north and south boundary (Fig. 4c), that is, the northerly moisture transport from the Barents and Kara Seas encountering the southerly warm moisture from the Arabian Sea in ECA. The regressed WAFs (Fig. 4d) showed that wave trains stimulated over the mid- to high-latitude North Atlantic eastward propagated and divided into two branches near western Eurasia. The north wave traveled to higher latitudes. The south wave propagated eastward and southeastward through Europe.
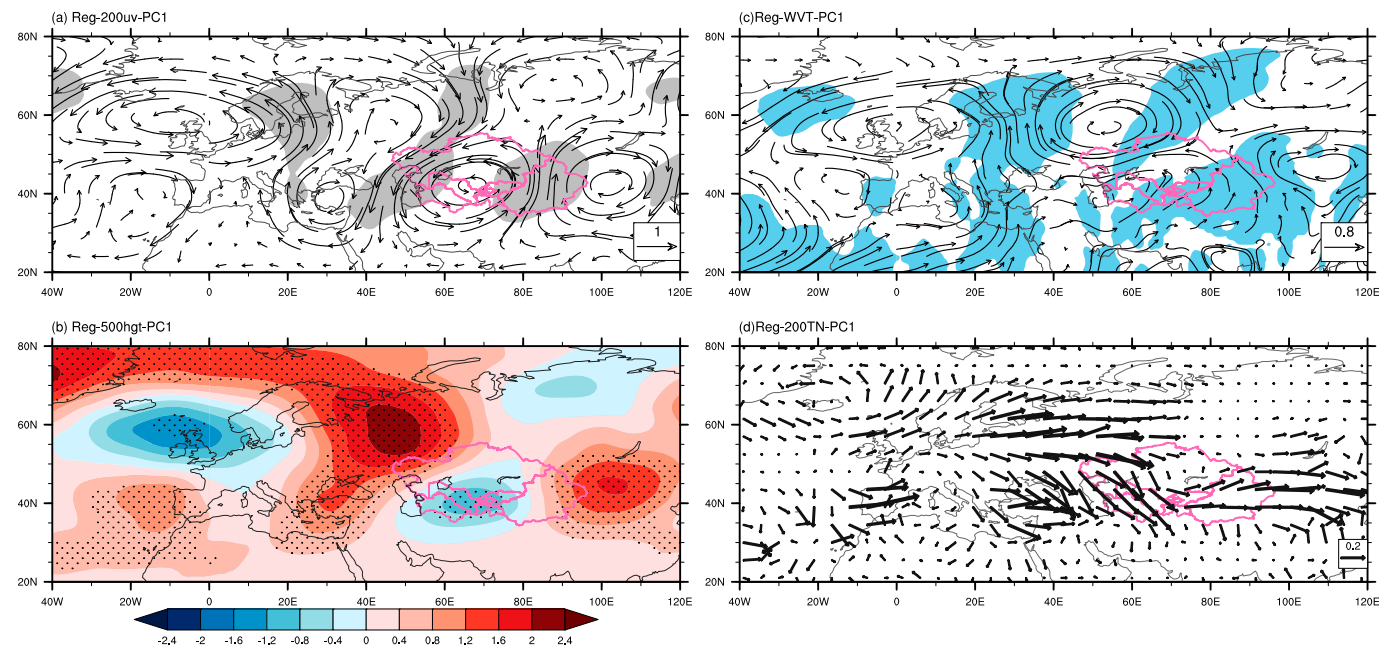

FIG. 4. Regression maps of PC1 against (a) 200-hPa wind velocity (vectors; $\mathrm{m} \mathrm{s}^{-1}$ ), (b) 500-hPa geopotential height (shading; gpm), (c) integrated WVT (vectors; unit: $10^{-4} \mathrm{~kg} \mathrm{~m}^{-2} \mathrm{~s}^{-1}$ ), and (d) 200-hPa WAFs (vectors; $\mathrm{m}^{2} \mathrm{~s}^{-2}$ ) during 1979-2018. Shading in (a) and (c) and dotted regions in (b) indicate values significantly exceeding the $90 \%$ confidence level estimated by Student's $t$ test. The pink contour outlines CA. 

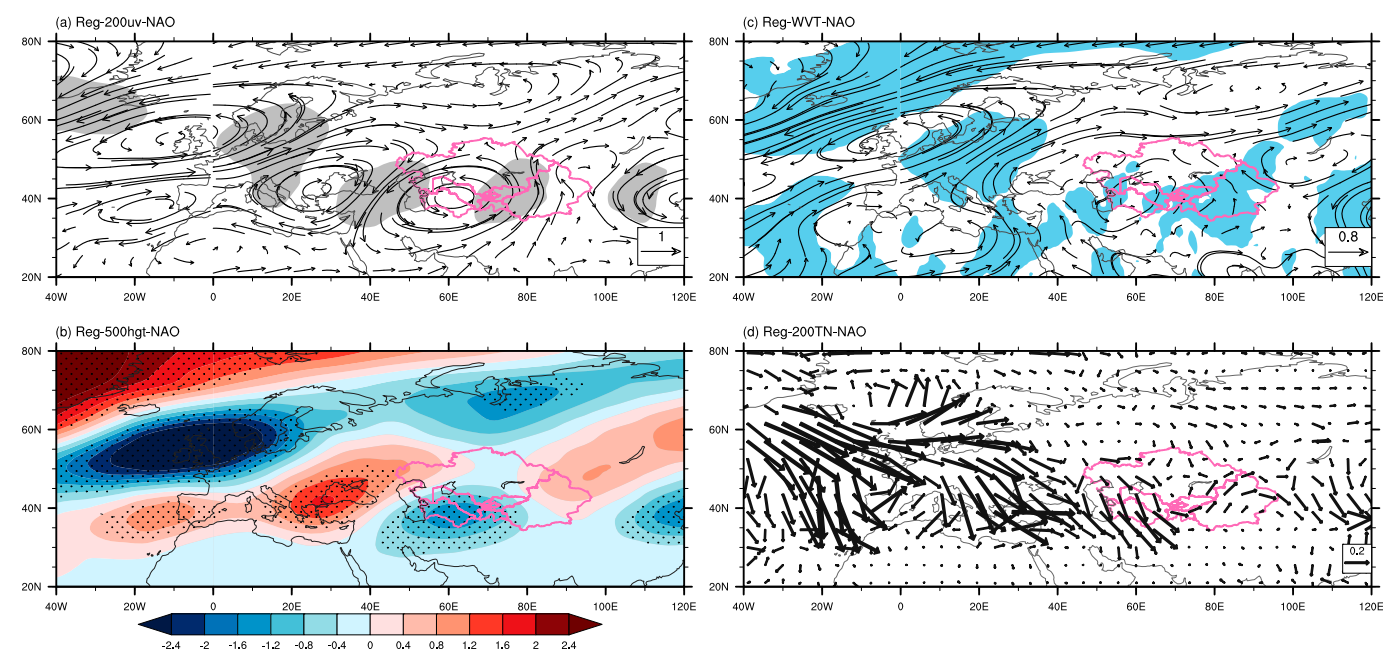

FIG. 5. As in Fig. 4, but for NAO (NAO index multiplied by -1).

Then, it traveled from the western CA and north CA and converged in ECA, which promoted extreme precipitation. The anomalous cyclones, converged WAFs, and favorable moisture conditions promoted extreme precipitation in ECA.

Previous studies have proposed that variations of NAO (Wang et al. 2013) and EA/WR (Ma et al. 2020) have close a relationship with atmospheric circulations over $\mathrm{CA}$, since the signal of the negative NAO and EA/WR in summer can result in the increased summer extreme precipitation in ECA. To examine the crucial roles of NAO and EA/WR in increased summer extreme precipitation in ECA, we further exhibited the regressed maps against NAO and EA/WR index in summer during 1979-2018 in Figs. 5 and 6, respectively. Figures $5 \mathrm{a}$ and $5 \mathrm{~b}$ show the regressed horizontal winds at $200 \mathrm{hPa}$ and geopotential height at $500 \mathrm{hPa}$ against the NAO index. The quasi-stationary wave could be found at mid- and high latitudes and was characterized by anomalous cyclones in the high-latitude North Atlantic, CA, northwest Eurasia, and East Asia and anomalous anticyclones in the midlatitude North
Atlantic, western Europe, and Lake Baikal. Correspondingly, the WVT also converged in ECA and strongly influenced by southwest moisture (Fig. 5c). The regressed WAFs in Fig. 5d divided into two branches near Ireland. The southern wave trains traveled eastward and southeastward and converged in the east Caspian Sea. In addition, cyclonic shear occurred over western Lake Balkhash, similar to Fig. 4d. Meanwhile, the regressed wind field at $200 \mathrm{hPa}$ (in Fig. 6a) and geopotential height at $500 \mathrm{hPa}$ (in Fig. 6b) against the EA/WR index were very similar to the regressed maps for $\mathrm{PC} 1$ and showed significant anomalous cyclones in CA. According to the regressed WVT, more northerly moisture from the Barents and Kara Seas was transported into ECA by the anomalous anticyclone over western Eurasia (Fig. 6c). Besides, strong WAFs propagated through the northern and northwestern boundary of CA and converged near the Balkhash Lake (Fig. 6d).

According to the Mann-Kendall test of PC1, extreme precipitation in ECA has experienced a significant abrupt change since 2000/01 (in Fig. 3c). We calculated the MTT of PC1 (not
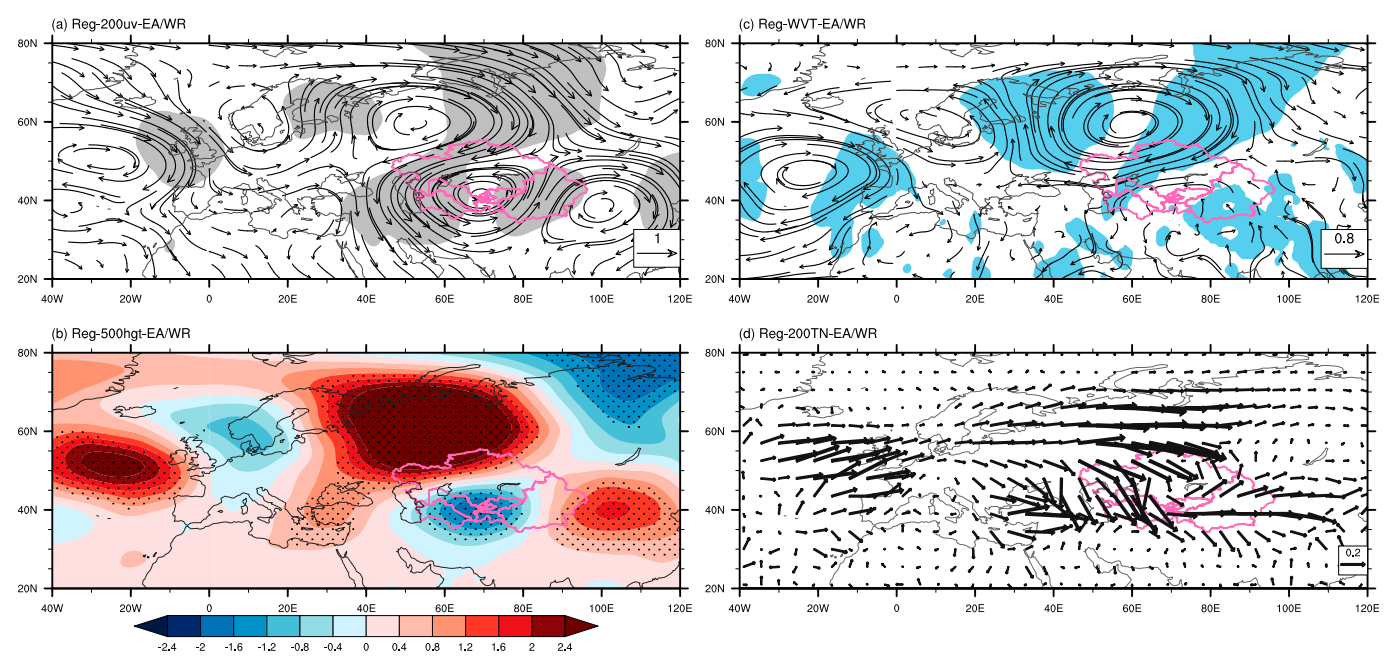

FIG. 6. As in Fig. 4, but for EA/WR (EA/WR index multiplied by -1). 

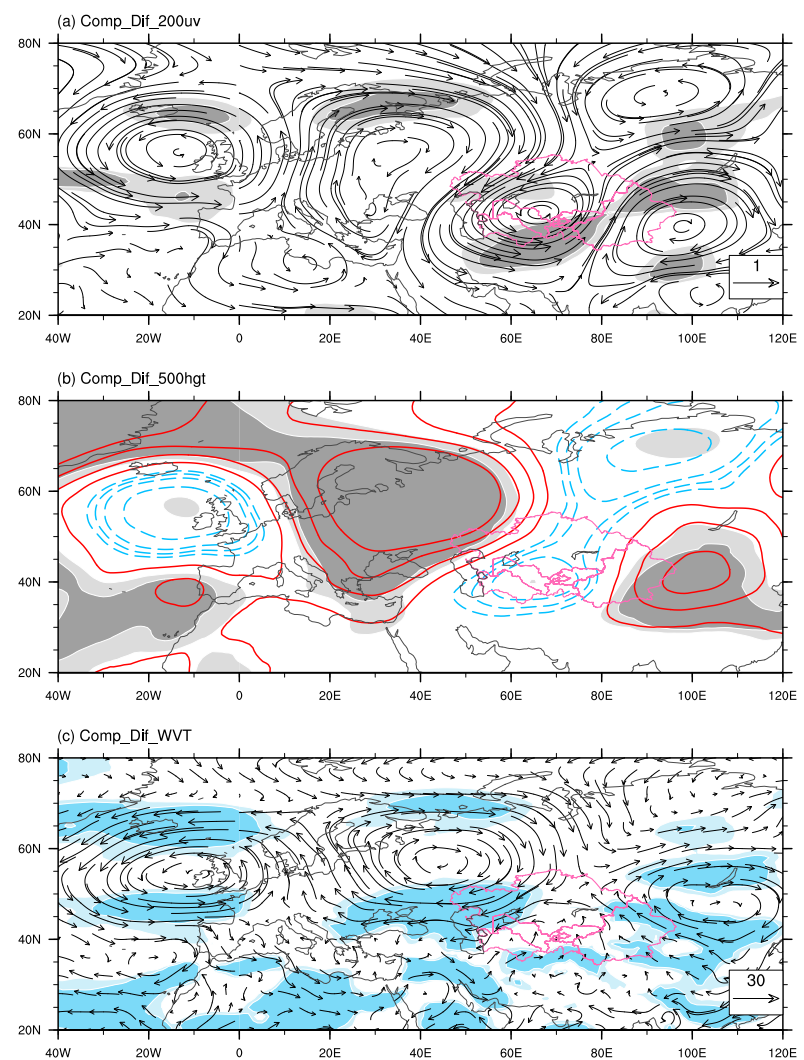

FIG. 7. Composite differences (1979-2000 minus 2001-18) in (a) 200-hPa wind field (vectors; unit: $\mathrm{m} \mathrm{s}^{-1}$ ), (b) 500-hPa geopotential height (contours; unit: gpm), and (c) integrated WVT (vectors; unit: $10^{-4} \mathrm{~kg} \mathrm{~m}^{-2} \mathrm{~s}^{-1}$ ). The shading from light to dark represent the $90 \%$ and $95 \%$ confidence level, respectively. The pink contour outlines CA.

shown), which also exhibited an interdecadal increase around 2000 (exceeding the 95\% confidence level). Composite differences (1979-2000 minus 2001-18) in the 200-hPa wind field, $500-\mathrm{hPa}$ geopotential height, and integrated WVT are exhibited in Fig. 7 to illustrate the interdecadal strengthening of the aforesaid anomalous circulation. The quasi-stationary wave patterns also prevailed at mid-high latitudes (Figs. 7a,b), which promoted anomalous cyclones centered in northern Iceland, CA, and northwestern Russia, and anomalous anticyclones over the mid- to low-latitude Atlantic, western Eurasia, and east of Xinjiang. Anomalous positive geopotential height centers in Scandinavia and East Asia significantly enhanced and strengthened negative geopotential height in CA. Figure $7 \mathrm{c}$ further displayed composite WVT differences, and increased extreme precipitation was influenced by anomalous moisture transports from north and south boundary (i.e., the northerly moisture transport by the anticyclone from the Barents and Kara Seas encountering the southwesterly warm moisture in ECA).

\section{2) The North Atlantic SST anomalies}

SST anomalies perpetually act as an important external forcing for extreme events (Li et al. 2018; Queralt et al. 2009). The North Atlantic plays crucial roles in Northern Hemisphere
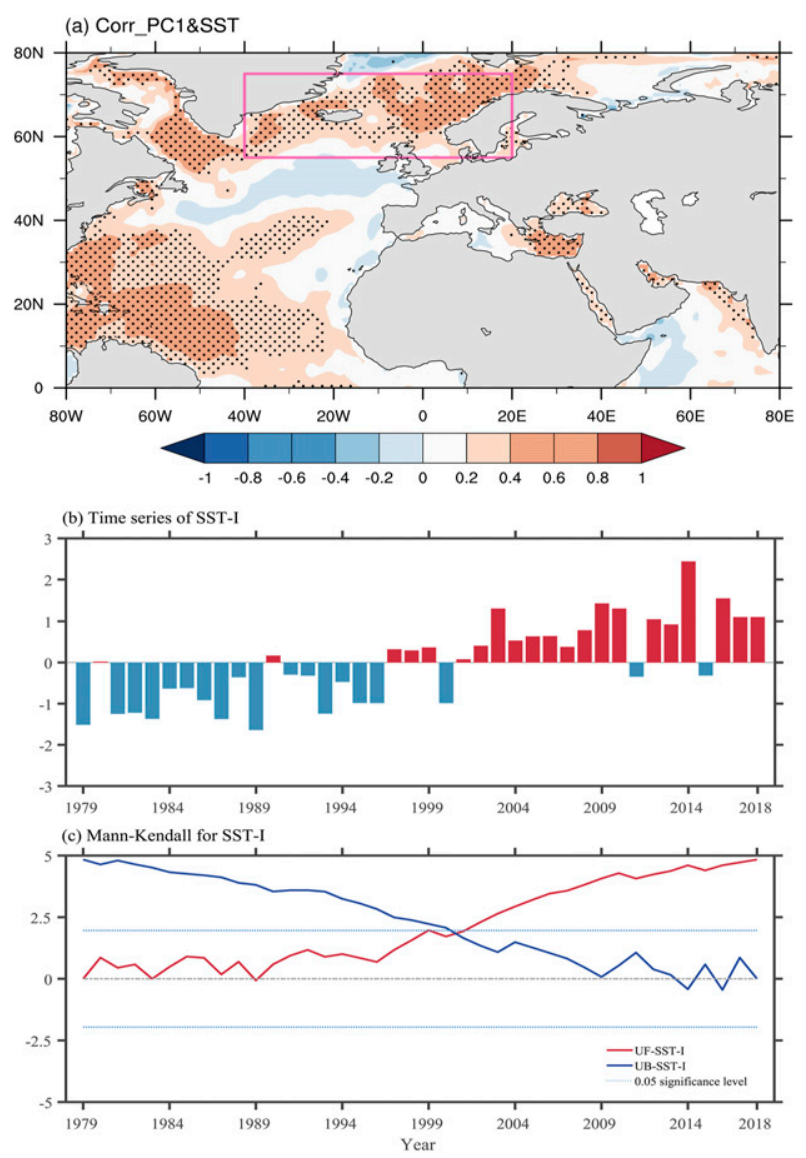

FIG. 8. (a) Correlation patterns between SST in JJA and PC1 for 1979-2018. Dotted areas indicated regions with significant correlations at the $95 \%$ confidence level. (b) The standardized time series of SST index (SST-I). (c) Mann-Kendall test of SST-I. UF and UB (red and blue solid lines, respectively) indicate the time series of the positive and inverse sequence calculation, and the dashed lines represented the $95 \%$ confidence level.

climate and extreme events (Kumar et al. 2017; Li et al. 2020; Lu et al. 2020; Queralt et al. 2009; J. Zhang et al. 2020). Figure 8 a further illustrates the correlation between PC1 and simultaneous SST in the North Atlantic. It is worth noting that the SST anomalies in the high-latitude North Atlantic were significantly correlated with PC1. To further illustrate the relationship between SST and extreme precipitation in ECA, we first defined a standardized areal weighted averaged SST index (SST-I) over $55^{\circ}-75^{\circ} \mathrm{N}, 40^{\circ} \mathrm{W}-20^{\circ} \mathrm{E}$ (red rectanglular area in Fig. 8a); Fig. 8 b shows the time series of SST-I (bars). The SST-I exhibited a significant increase during 1979-2018 and the correlation coefficient with PC1 was 0.47 (above $99 \%$ confidence level). The Mann-Kendall test results for the SST-I showed significant mutation and interdecadal increasing since 2000/01. The mutation change of PC1 (in 2000/01) is generally similar to that of SST-I. In addition, the mutation change of the NAO and EA/WR occurred around 2004. The period 2000-04 is regarded as an adjusting stage for SST anomalies, which was discussed by J. Zhang et al. (2020). Thus, the increased high-latitude North 

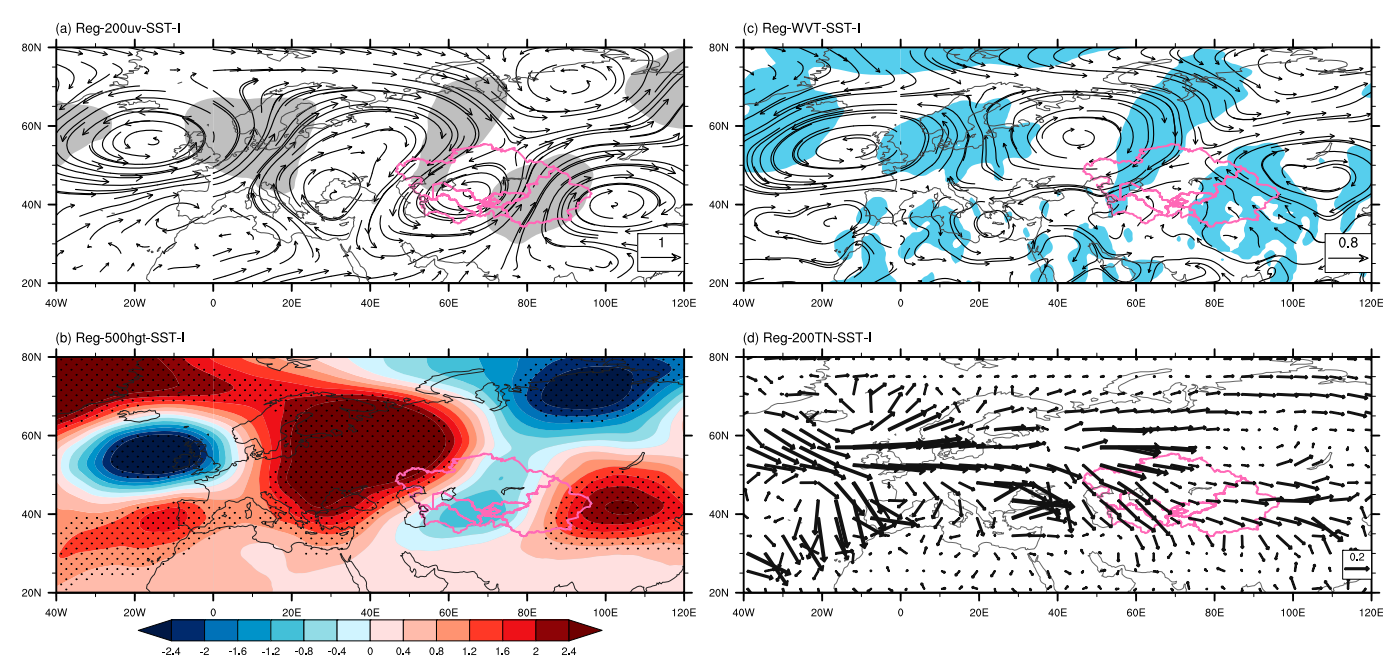

FIG. 9. As in Fig. 4, but for SST-I.

Atlantic SST is considered a key regulator of the increased extreme precipitation in ECA.

Accordingly, the atmospheric circulation anomalies associated with SST-I were investigated. Figures 9a and 9b showed the regressed horizontal winds at $200 \mathrm{hPa}$ and geopotential height at $500 \mathrm{hPa}$ against the SST-I. During 1979-2018, a quasistationary wave could be found in the mid- to high latitudes, exhibiting a distinct negative EA/WR pattern in western Eurasia and a negative NAO pattern in the North Atlantic. This circulation pattern is similar to those in Figs. 4a and 4b. Anomalous cyclones in CA were accompanied with significant northerly water vapor transportation to ECA (in Fig. 9c). Meanwhile, significant southerly water vapor was transported to Xinjiang. Figure 9d plotted the regressed WAF against the SST-I; although the southern pathway is relatively weaker with respect to Fig. $4 d$, it can be seen that the energy propagation is quite consistent with Fig. 4d.

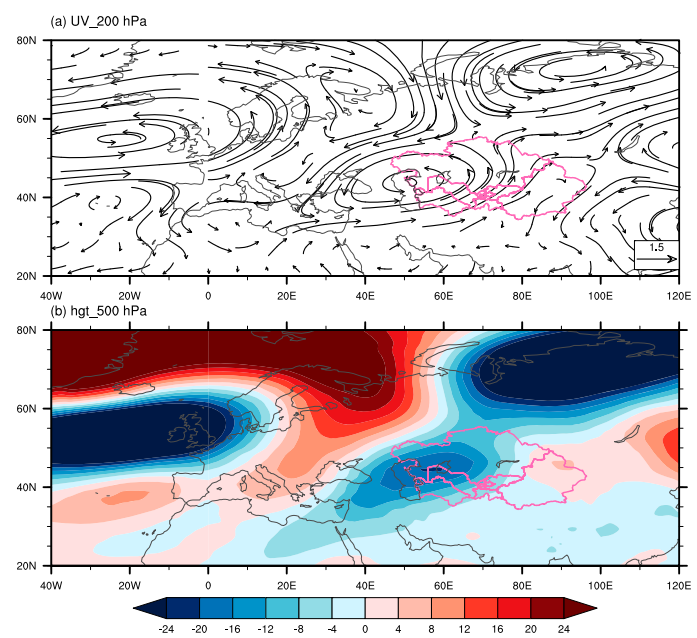

To further examine the influence of the high-latitude North Atlantic SST on extreme precipitation in ECA, two numerical experiments were conducted with different SST conditions over $55^{\circ}-75^{\circ} \mathrm{N}, 40^{\circ} \mathrm{W}-20^{\circ} \mathrm{E}$ (red rectangular area in Fig. 8) during JJA. The two experiments include a control and a sensitivity experiment. The sensitivity experiment used the SST condition of control experiment plus the SST anomalies over $55^{\circ}-75^{\circ} \mathrm{N}$, $40^{\circ} \mathrm{W}-20^{\circ} \mathrm{E}$ during $1979-2018$, where the SST anomalies are calculated based on the HadISST data. Figure 10a shows the response of anomalous wind field at $200 \mathrm{hPa}$, geopotential height at $500 \mathrm{hPa}$, precipitation, and WVT to the increased high-latitude North Atlantic SST. Anomalous anticyclones are centered in Kola Peninsula, $40^{\circ} \mathrm{N}$ in the North Atlantic, and East Asia. Anomalous cyclones can be found in western Ireland, the eastern Caspian Sea, and northwestern Russia. Moreover, distinct negative EA/WR and NAO patterns have been captured in western Eurasia and the North Atlantic (Figs. 10a,b). The WVT
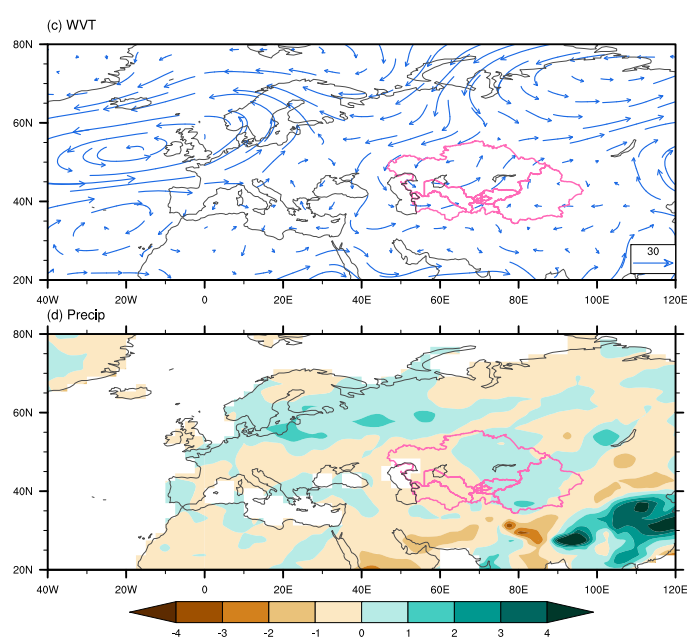

FIG. 10. Summer mean climatic (a) 200-hPa wind (vectors; unit: $\mathrm{m} \mathrm{s}^{-1}$ ), (b) 500-hPa geopotential height (shading; unit: gpm), (c) integrated WVT (vectors; unit: $10^{-4} \mathrm{~kg} \mathrm{~m}^{-2} \mathrm{~s}^{-1}$ ), and (d) precipitation (shading; mm) field anomalies forced by SST in the high-latitude North Atlantic for 40 years captured by the CAM5.1 model. 
transportation was basically consistent with that in Fig. 4c with anomalous cyclonic anomalies appearing in CA (Fig. 10c). Moisture anomalies from the Barents and Kara Seas and southwesterly WVT strongly converged in ECA, which was beneficial to extreme precipitation in ECA (Fig. 10d). The above results indicate influences of the increased SST in high-latitude North Atlantic on the precipitation in ECA by the numerical model, which is mainly consistent with the diagnostic results.

In summary, the increased extreme precipitation in ECA was adjusted by a quasi-stationary wave train in mid- to high-latitude Eurasia that is closely related to the negative NAO and EA/WR pattern. This wave train showed significant interdecadal strengthening since 2000 and led to more extreme precipitation events in ECA. Both the diagnosis and numerical simulations showed that the increased extreme precipitation was adjusted by the increased high-latitude North Atlantic SST anomalies. Meanwhile, the SST anomalies also interacted with NAO and EA/WR.

\section{c. Impact of synoptic-scale circulation}

Previous studies showed that extreme precipitation events are closely related to large-scale atmospheric circulation and SST variability (Deng et al. 2014; Hu et al. 2015; Liu et al. 2015; Park et al. 2009; J. Zhang et al. 2020). However, the occurrence of extreme precipitation is usually sudden and at synoptic scale. Systematic views of multiscale interaction effects on extreme precipitation are rare, especially in CA. The synoptic transient waves in the Northern Hemisphere are mainly active in the latitudinal elongation regions of the Pacific Ocean and the Atlantic Ocean (Blackmon 1976), and Eurasia acts as a breeding ground for transient waves that closely relate to Eurasian extreme weather and climate events (Chen et al. 2013; Giannakaki and Martius 2016; Nakamura et al. 2002). Therefore, the transient wave activities are primarily considered.

\section{1) IMPACT OF SYNOPTIC-SCALE EDDIES}

We first calculated the transient waves coincident with 200 extreme precipitation events in ECA. The composited $v$ was analyzed via EOF analysis, and the first two EOF modes were shown in Fig. 11. The first two EOF modes can be significantly separated from others by North's test (North et al. 1982), and results showed two typical transient wave propagation paths. Consistent with previous research results (Chen et al. 2013), two significant transient wave trains were also shown over Eurasia in summer. The transient waves were stimulated from the North Atlantic Ocean and propagated through Eurasia. The south branch was mainly active near $38^{\circ} \mathrm{N}$ with a relatively narrow belt (Fig. 11a), and weakened near the western Caspian Sea, displaying a cyclone transient eddy. The north branch was stronger and had a wider propagation path than the south branch (Fig. 11b). It actively propagated along $50^{\circ}-$ $55^{\circ} \mathrm{N}$ and guided a cyclone transient eddy over the eastern CA. The first and second EOF mode mainly captured the south and north branch, respectively. Ren et al. (2011) diagnosed that the East Asian subtropical jet and polar-front jet correlated with the synoptic-scale transient eddy in winter Eurasia. Our analysis showed a quasi-stationary circulation in the mid- to high Eurasian latitudes, which guided anomalous cyclones over CA. When the two typical transient wave trains propagated and
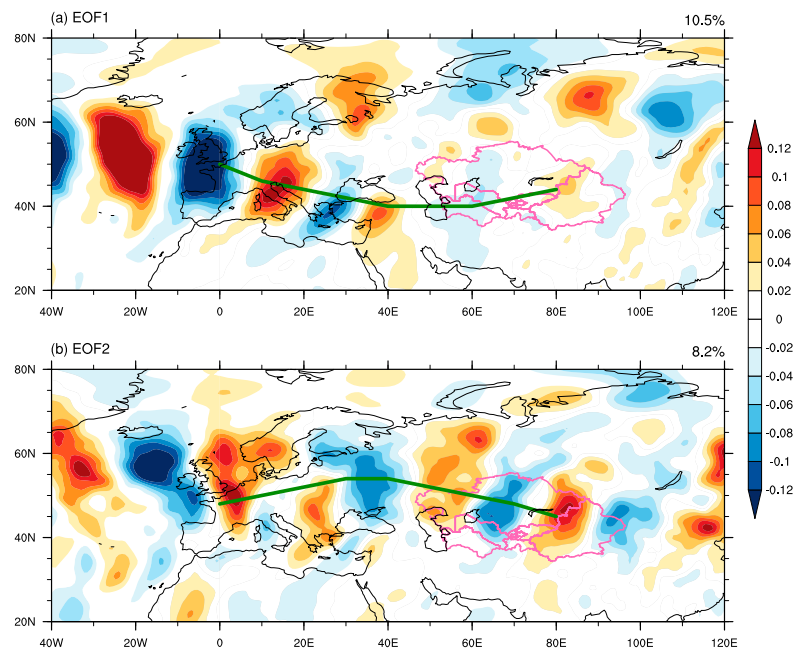

FIG. 11. The spatial pattern of the first two EOF modes of transient waves $\left(v^{\prime}\right)$ at $300 \mathrm{hPa}$. The number and asterisk represent the total variances and statistical significance and independence from other modes according to North's test, respectively. Green lines denote the main paths of the transient waves.

superimposed on the quasi-stationary wave, the Lake Balkhash trough deepened. Meanwhile, the transient eddy was stimulated over CA, which further provided disturbance kinetic energy and favorable conditions for extreme precipitation.

The following section further describes the impacts of transient wave activity on extreme precipitation via composited extreme precipitation events. Considering the temporal evolution of $\overline{v^{\prime 2}}$ at $300 \mathrm{hPa}$ from the day before to the day after the precipitation, two different $\overline{v^{\prime 2}}$ distributions shown in Fig. 12. Among the selected extreme precipitation events $40 \%$ were affected by the north transient wave, $13 \%$ by the south transient wave, and the rest were caused by the joint influence of the two waves or other reasons. In Fig. 12, the left composited events as shown were influenced by the south transient wave (Figs. 12a-c) and the right were typical north transient wave (Figs. 12d-f). Uniformly, before the precipitation, ${\overline{v^{\prime}}}^{2}$ was weak. The transient waves were strong and coherent in the west Caspian Sea (Figs. 12a,b). With the occurrence of extreme precipitation, the south and north transient waves were much stronger and more active, occurring successively in CA (Figs. 12b,d). The north wave train was stronger and more successive than the south one and more likely to induce extreme precipitation. After extreme precipitation, transient waves gradually decreased and left CA (Figs. 12c,f). In addition, the extreme precipitation events affected by transient waves occurred $38 \%$ before 2000 and $62 \%$ after 2000 , which means transient wave activity also enhanced since 2000 .

\section{2) IMPACT OF VORTICITY ADVECTION}

Regarding the synergistic synoptic and large-scale effects on extreme precipitation in ECA from diagnosis, although the relationships between the quasi-stationary wave activity and synoptic activity are complex, their synergistic effects on extreme precipitation in ECA have been clearly evidenced in the following arguments. 

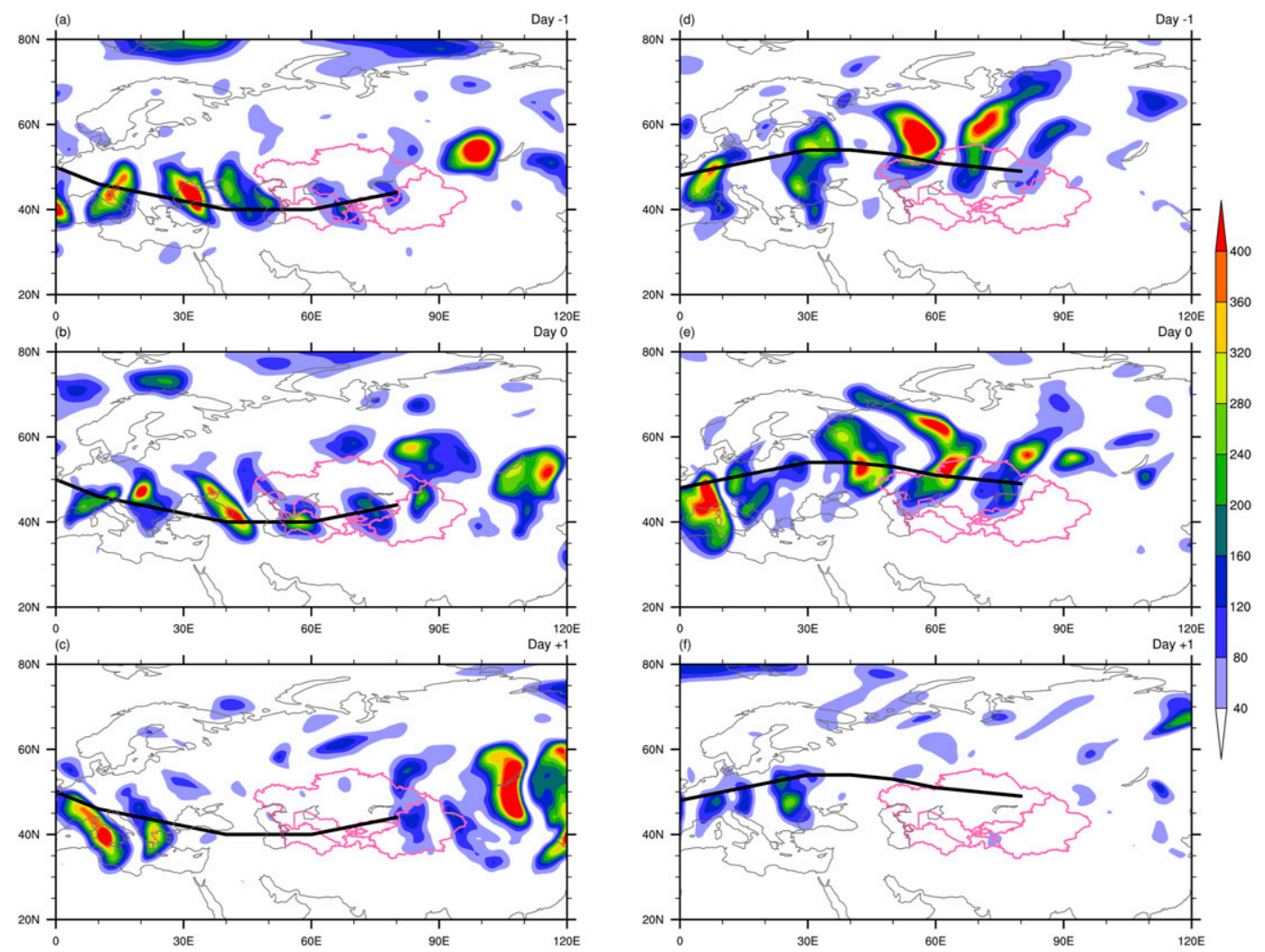

FIG. 12. Temporal evolution of composited daily transient wave intensity $\overline{v^{\prime 2}}$ at $300 \mathrm{hPa}$ over the base point $\left(40^{\circ} \mathrm{N}\right.$, $80^{\circ} \mathrm{E}$ ) from day -1 to day 1 for the (left) south and (right) north transient wave. The solid black line indicates the path of the transient waves.

The quasi-stationary wave train deepens the Lake Balkhash trough and guides the southwest and north moisture convergence affecting extreme precipitation in ECA. Meanwhile, the synoptic-scale transient wave enhances the disturbance kinetic energy. Thus, we used the quasigeostrophic vorticity equation to diagnose vorticity advection, which influences the formation of vertical motions via adiabatic processes (Kosaka et al. 2011; Miao et al. 2019). According to the meridional vorticity advection regression maps against $\mathrm{PC} 1$ during two subperiods (Fig. 13), most areas in CA had no significant meridional vorticity advection in 1979-2000 (Fig. 13a). After 2000, the positive meridional vorticity dominated the ECA, which implied that increased extreme precipitation in ECA impacted by the increased southerly vorticity advection. Meanwhile, the southerly vorticity advection guided warm moisture from the Arabian Sea (Fig. 4c) into the updraft, promoting extreme precipitation.

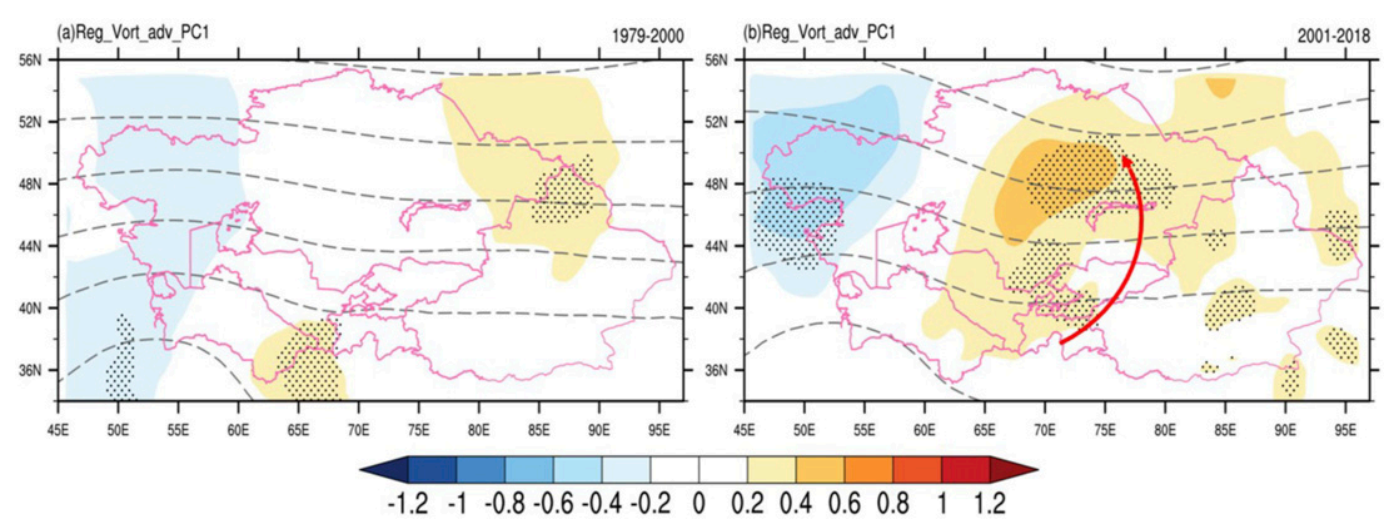

FIG. 13. Regression maps of PC1 against meridional vorticity advection (shading; unit: $10^{-11} \mathrm{~s}^{-2}$ ) and climatological geopotential height (black dashed lines; unit: gpm) during (a) 1979-2000 and (b) 2001-18. Dots indicate significance at the $90 \%$ confidence level. 

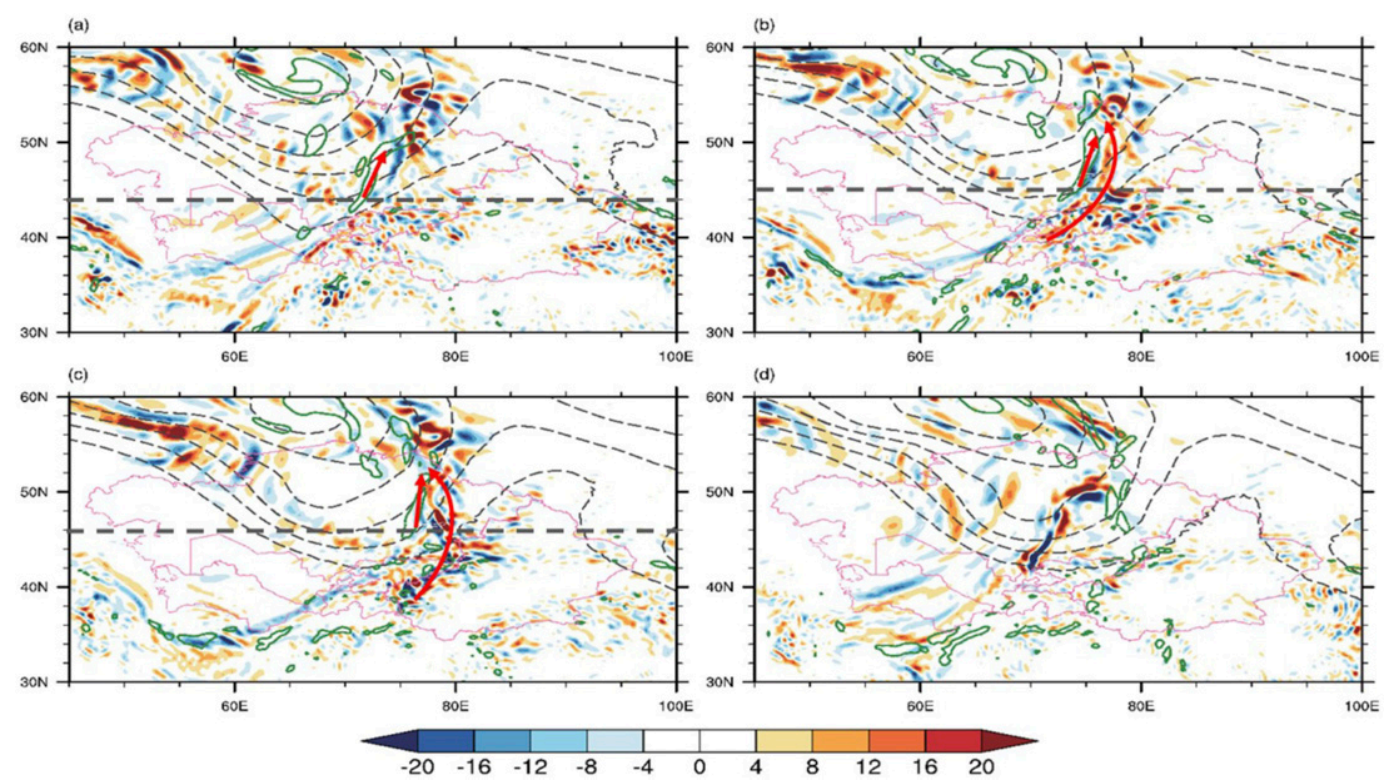

FIG. 14. Vorticity advection (shading; unit: $10^{-11} \mathrm{~s}^{-2}$ ), positive vorticity images (green contours; value: $1 \times$ $10^{-4} \mathrm{~s}^{-1}$ ), and geopotential height (black dashed lines; unit: gpm) at $500 \mathrm{hPa}$ at (a) 0800 , (b) 1200 , (c) 1600 , and (d) 2000 LT 14 July 2016.

Additionally, we choose the extreme precipitation events on 14 July 2016 to see the temporal evolution of vorticity advection characteristics that had been reported at http:// www.weather.com.cn/. At 0800 local time (LT), a trough located near $63^{\circ} \mathrm{E}$ and positive vorticity was active in eastern Kazakhstan (Fig. 14a). At 1200 LT, the trough moved slightly eastward to the $67^{\circ}$ E near Lake Balkhash (Fig. 14b). Stronger positive vorticity advection was exhibited in eastern Kazakhstan and the Tianshan Mountain range, and more positive vorticity from south CA propagated into ECA along the trough. Meanwhile, the trough was deepened southward. With the persistence of extreme precipitation, stronger positive vorticity advection and more positive vorticity occurred in ECA. In addition, the special terrain of the Tianshan Mountains could stimulate more vorticity and further enhance extreme precipitation in the aforementioned regions (Fig. 14c). The position of the trough stabilized near $67^{\circ} \mathrm{E}$ from 1200 to $1600 \mathrm{LT}$, which created beneficial conditions for positive vorticity advection and positive vorticity generation in the Tianshan Mountain range and transport to eastern Kazakhstan. These processes were conducive to forming and sustaining extreme precipitation in ECA. Until $2000 \mathrm{LT}$, the trough and vorticity advection and precipitation began to weaken (Fig. 14d).

Satellite cloud images can better monitor the evolution of meso- to microscale convective precipitation. Thus, the coinstantaneous $F Y-2 G$ TBB images were employed to vividly depict the aforementioned extreme precipitation event in Fig. 15. At 0800 LT, an isolated cloud cumulus was generated to the northwest of Lake Balkhash and slowly moved in eastward (Fig. 15a). At 1200 LT, a cumulus monomer with $\mathrm{TBB}$ below $-50^{\circ} \mathrm{C}$ strengthened and moved eastward (Fig. 15b). Its southern band was strengthened in the Tianshan Mountains region, corresponding to positive vorticity. At $1600 \mathrm{LT}$, the southern band was further enhanced and the cumulus monomer stabilized in east CA (Fig. 15c). Finally, the clouds gradually moved northward with the decreased precipitation (Fig. 15d).

\section{Summary and discussion}

In this study, we have investigated and explored extreme precipitation variability in the key region of central Asia (CA), and discussed the multiscale circulation configuration scheme and its possible mechanisms (Fig. 16).

In $\mathrm{CA}$, frequent and intensified extreme precipitation occurred mainly in the eastern regions (ECA). The spatial pattern of extreme precipitation exhibited a quasi-monopole pattern in ECA and showed a significant interdecadal increasing trend since 2000/01, which was mainly influenced by the increased high-latitude North Atlantic SST anomalies. The SST anomaly stimulated a quasi-barotropic wave train near $30^{\circ}-60^{\circ} \mathrm{N}$. Then, it propagated along mid- to high-latitude Eurasia. The wave train was related to the negative NAO and EA/WR teleconnection pattern and guided a cyclonic anomaly in CA. Meanwhile, it exhibited an energy sink and deepened the quasi-stationary wave trough around Lake Balkhash and further enhanced the cyclonic anomaly in CA. An enhanced anticyclone in western Eurasia favored moisture advection from the Barents Sea southward into ECA. Moreover, the deepened wave trough extended southward and guided the moisture southward, which encountered abundant warm moisture from the Arabian Sea and generated extreme precipitation in ECA. The above conclusions were 

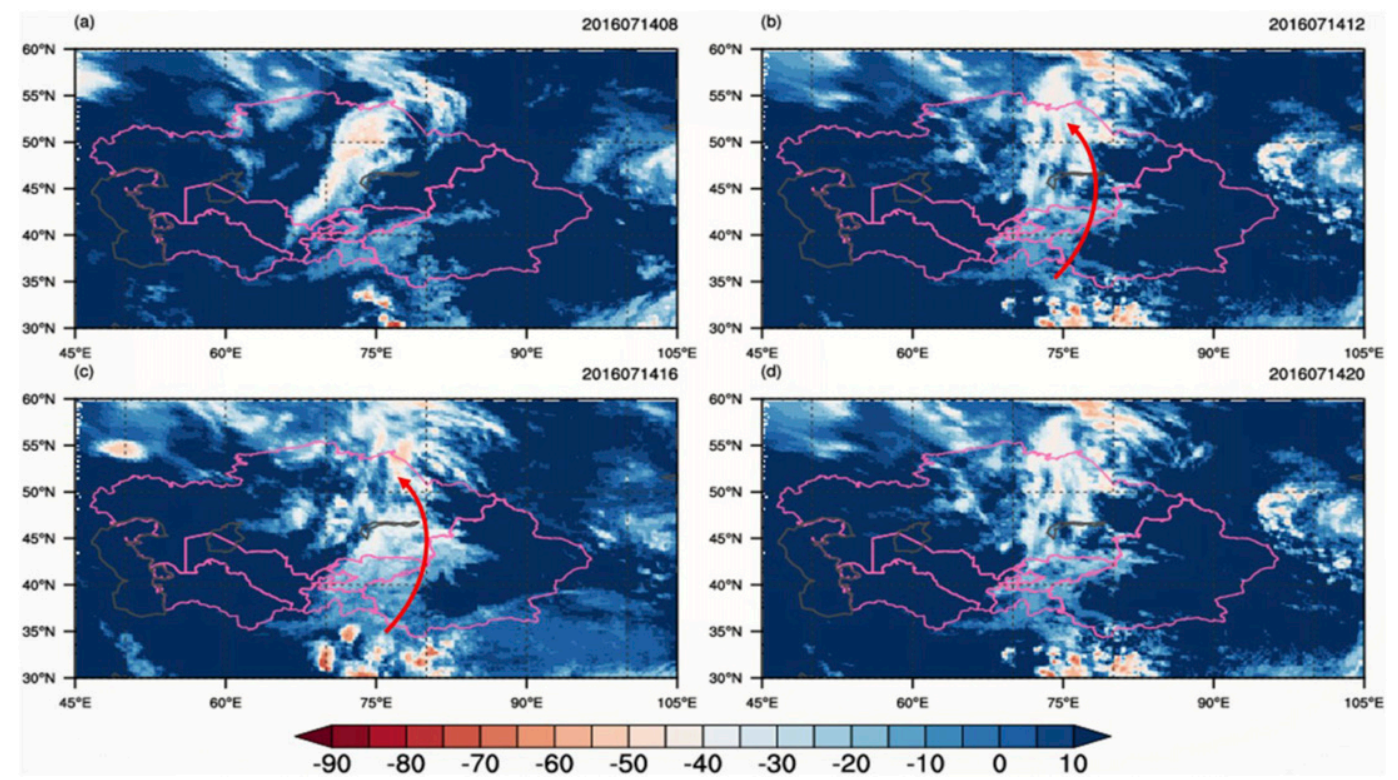

FIG. 15. Satellite hourly TBB images from $F Y-2 G$ (unit: ${ }^{\circ} \mathrm{C}$ ) at (a) 0800, (b) 1200 , (c) 1600, and

(d) 2000 LT 14 Jul 2016.

also confirmed in the model simulations. Additionally, we found a high correlation between low-latitude North Atlantic SST $\left(5^{\circ}-40^{\circ} \mathrm{N}, 80^{\circ}-40^{\circ} \mathrm{W}\right)$ and extreme precipitation in ECA (Fig. 8a). Moreover, the SST of these region has a higher correlation with AMO about 0.88 (exceeding 99\% confidence level), which is much higher than the SST-I about 0.40 (exceeding 95\% confidence level). Previous studies showed that the dominant mode of the North Atlantic is the AMO (Schlesinger and Ramankutty 1994). J. Zhang et al. (2020) found that the AMO can influence the eastward shift of the negative NAO

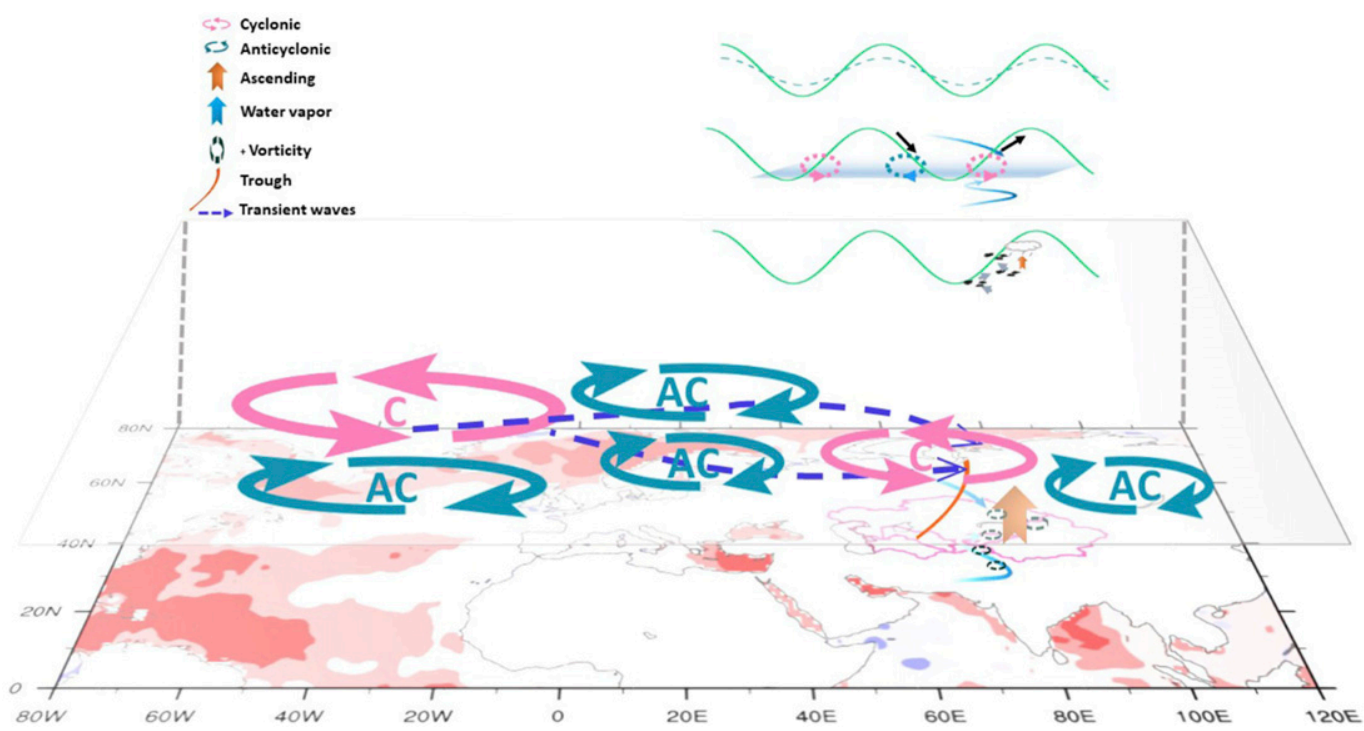

FIG. 16. Schematic diagram to illustrate the physical processes associated with the increased extreme precipitation in ECA. When extreme precipitation increases, the increased SST in the high-latitude North Atlantic modified the quasi-stationary wave train, guided the cyclonic anomaly in CA, deepened the Lake Balkhash trough, enhanced the anticyclonic anomaly in western Eurasia, and advected moisture southward. Two synoptic transient wave trains strengthen the amplitude of the quasi-stationary waves and guide transient eddies in eastern CA. The induced transient eddy and deepened Lake Balkhash trough strengthened positive meridional vorticity advection and local positive vorticity was strengthened by the terrain of the Tianshan, which promoted ascending motions, guiding the southerly warm moisture and further increasing extreme precipitation in ECA. 
pattern and magnified amplitudes of the quasi-stationary waves over Eurasia. Multiple factors influence the low-latitude North Atlantic SST variability (Lu et al. 2020; Wang 2019). Thus, more work is needed to refine the influence of low-latitude North Atlantic SST on extreme precipitation in CA.

Two distinct transient wave trains were also shown in midand high-latitude Eurasia accompanying extreme precipitation in ECA. The activity range of the northern synoptic-scale transient wave train was wider and more significant than that of the southern one. Both activities of transient waves were beneficial for the magnifying amplitudes of the quasi-stationary waves and generated transient eddies in ECA, which enhanced the vortex ahead of the wave trough, increasing the probability of extreme precipitation in ECA (Chen and Zhai 2013; Miao et al. 2019). Extreme precipitation occurred with strong and continuous transient wave trains. Both the quasi-stationary and transient wave trains were strongest in the north and had barotropic structure. Meanwhile, the southern one was less obvious, which may be influenced by the Iranian and Tibetan Plateaus (Miao et al. 2019; Zhao et al. 2014). Generally, the confluence of wave trains enhanced cyclonic anomalies, WVT, and WAF convergence in ECA, and the enhanced transient eddy further increased extreme precipitation in ECA.

The vertical motion in front of the wave trough also played an essential role in the formation of extreme precipitation. According to the diagnosed vorticity advection, the vertical motion was mainly caused by the southerly vorticity advection and synoptic transient waves, which were significantly strengthened after 2000. At extreme precipitation events, positive relative vorticity and southerly vorticity advection moved along the Lake Balkhash trough and guided moisture into updrafts. Meanwhile, with the strong meridional circulation and mesoscale topography characteristics along the west of the Tianshan Mountains, more positive mesoscale vorticity was generated, further enhancing extreme precipitation in ECA. These diagnostic results were also displayed by satellite images. The mechanisms of the aforesaid multiscale synergy on extreme precipitation in ECA were summarized in Fig. 16. Extreme precipitation in ECA displayed a quasi-monopole increasing pattern with abrupt change since 2000/01, which was likely dominated by increased high-latitude North Atlantic SST anomalies. Increased SST via adjusting the quasi-stationary wave train related to the negative NAO and the EA/WR pattern guided the cyclonic anomaly in $\mathrm{CA}$, deepened the Lake Balkhash trough, and enhanced the moisture convergence in ECA. After 2000, the activities of transient waves showed increasing trends, which would further increase the disturbance kinetic energy, facilitate the amplification of quasi-stationary wave amplitude, and lead to more transient activities in ECA. The deepened Lake Balkhash trough was advantageous to positive vorticity advection northward transport and aroused transient eddies on the west side of the Tianshan, which further enhanced the uplift and the water vapor convergence in front of the trough. Transient eddies propagated along the trough to northern Kazakhstan, eventually leading to extreme precipitation in ECA.

Extreme precipitation usually links with several key atmospheric circulation anomalies induced by teleconnection patterns (Archambault et al. 2008; Chen and Zhai 2014). In this study, results indicated that a quasi-stationary and transient wave train can provide vital circulation conditions for the formation of extreme precipitation in ECA from a multiscale synergy aspect. Besides, several other factors may be responsible for extreme precipitation in ECA, such as the westerly jet, which can lead to upper-level divergence (Wang et al. 2011), the Tibetan and Iranian Plateau thermal effects (Zhao et al. 2014), the SST anomaly in the Indian Ocean, and the El Niño influences (Kug et al. 2006; Huang et al. 2015). The temperature increase in CA is more prominent than the global average during the latest decades ( $\mathrm{Hu}$ et al. 2014). The atmospheric water cycle has enhanced under global warming (Bosilovich 2013) and the correlations between increased temperature and extreme precipitation in CA need more attentions. Besides, Tianshan Mountain topography is crucial for precipitation in CA via adjusting the uplift (Sha et al. 2018; Zhong et al. 2017). Additionally, this study also indicated that the terrain of the Tianshan Mountain range can enhance extreme precipitation in ECA via increasing the vorticity and vorticity advection. However, these findings are not sufficient and deserve further investigation to reach a deep and comprehensive understanding of multiscale synergy mechanisms.

Acknowledgments. This research was jointly supported by the National Key R\&D Program of China (Grant 2018YFC1507101), the National Natural Science Foundation of China (Grant 41975083), and the Priority Academic Program Development of the Jiangsu Higher Education Institutions (PAPD).

\section{REFERENCES}

Alexander, L. V., X. B. Zhang, T. C. Peterson, J. Caesar, and J. L. Vazquez-Aguirre, 2006: Global observed changes in daily climate extremes of temperature and precipitation. J. Geophys. Res., 111, D05109, https://doi.org/10.1029/2005JD006290.

Archambault, H. M., L. F. Bosart, D. Keyser, and A. R. Aiyyer, 2008: Influence of large-scale flow regimes on cool-season precipitation in the northeastern United States. Mon. Wea. Rev., 136, 2945-2963, https://doi.org/10.1175/2007MWR2308.1.

Blackmon, M. L., 1976: A climatological spectral study of the $500 \mathrm{mb}$ geopotential height of the Northern Hemisphere. J. Atmos. Sci., 33, 1607-1623, https://doi.org/10.1175/15200469(1976)033<1607:ACSSOT>2.0.CO;2.

Bosilovich, M. G., 2013: Regional climate and variability of NASA MERRA and recent reanalyses: U.S. summertime precipitation and temperature. J. Appl. Meteor. Climatol., 52, 1939-1951, https://doi.org/10.1175/JAMC-D-12-0291.1.

Bothe, O., K. Fraedrich, and X. Zhu, 2011: Precipitation climate of central Asia and the large-scale atmospheric circulation. Theor. Appl. Climatol., 108, 345-354, https://doi.org/10.1007/ s00704-011-0537-2.

Bueh, C., S. Ning, and Z. Xie, 2011: Large-scale circulation anomalies associated with persistent low temperature over southern China in January 2008. Atmos. Sci. Lett., 12, 273-280, https://doi.org/10.1002/asl.333.

Buri, D., J. Lukovi, B. Bajat, M. Kilibarda, and V. Duci, 2015: Recent trends in daily rainfall extremes over Montenegro (1951-2010). Nat. Hazards Earth Syst., 3, 2347-2377.

Carroll, E. B., 2006: Thermal advection, vorticity advection and potential vorticity advection in extra-tropical, synoptic-scale 
development. Meteor. Appl., 10, 281-292, https://doi.org/ 10.1017/S1350482703003086.

Chen, F., and Coauthors, 2008: Holocene moisture evolution in arid central Asia and its out-of-phase relationship with Asian monsoon history. Quat. Sci. Rev., 27, 351-364, https://doi.org/ 10.1016/j.quascirev.2007.10.017.

_ - J. Wang, L. Jin, Q. Zhang, L. I. Jing, and J. Chen, 2009: Rapid warming in mid-latitude central Asia for the past 100 years. Front. Earth Sci. China, 3, 42-50, https://doi.org/10.1007/ s11707-009-0013-9.

_ Asia: Spatiotemporal differences in climate change and possible mechanisms on decadal to sub-orbital timescales. Earth-Sci. Rev., 192, 337-354, https://doi.org/10.1016/j.earscirev.2019.03.005.

Chen, H., and J. Sun, 2017: Contribution of human influence to increased daily precipitation extremes over China. Geophys. Res. Lett., 44, 2436-2444, https://doi.org/10.1002/2016GL072439.

Chen, H. S., L. Liu, and Y. J. Zhu, 2012: Possible linkage between winter extreme low temperature events over China and synoptic-scale transient wave activity. Sci. China Earth Sci., 42, 1951-1965.

—, Y. Zhu, and L. Liu, 2013: Relationship of synoptic-scale transient eddies and extreme winter precipitation events in the middle and lower reaches of the Yangtze River (in Chinese). Chin. J. Atmos. Sci., 37, 801-814.

Chen, M., W. Shi, P. Xie, V. B. S. Silva, V. E. Kousky, R. W. Higgins, and J. E. Janowiak, 2008: Assessing objective techniques for gauge-based analyses of global daily precipitation. J. Geophys. Res., 113, D04110, https://doi.org/10.1029/ 2007JD009132.

Chen, Y., and P. Zhai, 2013: Persistent extreme precipitation events in China during 1951-2010. Climate Res., 57, 143-155, https://doi.org/10.3354/cr01171.

$\longrightarrow$, and — 2014: Precursor circulation features for persistent extreme precipitation in central-eastern China. Wea. Forecasting, 29, 226-240, https://doi.org/10.1175/WAF-D-13-00065.1.

Chen, Z., and J. Zhang, 2020: The characteristics of late summer extreme precipitation in northern China and associated largescale circulations. Int. J. Climatol., 40, 5170-5187, https:// doi.org/10.1002/joc.6512.

Cui, W., X. Dong, B. Xi, and A. Kennedy, 2017: Evaluation of reanalyzed precipitation variability and trends using the gridded gauge-based analysis over the CONUS. J. Hydrometeor., 18, 2227-2248, https://doi.org/10.1175/JHM-D-17-0029.1.

Dee, D. P., S. M. Uppala, A. J. Simmons, P. Berrisford, P. Poli, and S. Kobayashi, 2011: The ERA-Interim reanalysis: Configuration and performance of the data assimilation system. Quart. J. Roy. Meteor. Soc., 137, 553-597, https://doi.org/10.1002/qj.828.

Deng, H., Y. Chen, X. Shi, W. Li, H. Wang, S. Zhang, and G. Fang, 2014: Dynamics of temperature and precipitation extremes and their spatial variation in the arid region of northwest China. Atmos. Res., 138, 346-355, https://doi.org/10.1016/ j.atmosres.2013.12.001.

Ding, F., and C. Li, 2017: Subtropical westerly jet waveguide and winter persistent heavy rainfall in south China. J. Geophys. Res., 122, 7385-7400, https://doi.org/10.1002/2017JD026530.

Donat, M. G., L. V. Alexander, N. Herold, and A. J. Dittus, 2016a: Temperature and precipitation extremes in century-long gridded observations, reanalyses, and atmospheric model simulations. J. Geophys. Res., 121, 11174-11189, https:// doi.org/10.1002/2016JD025480.

— A. L. Lowry, L. V. Alexander, P. A. O'Gorman, and N. Maher, 2016b: More extreme precipitation in the world's dry and wet regions. Nat. Climate Change, 6, 508-513, https:// doi.org/10.1038/nclimate2941.

Du, H., Z. Wu, S. Zong, X. Meng, and L. Wang, 2013: Assessing the characteristics of extreme precipitation over northeast China using the multifractal detrended fluctuation analysis. J. Geophys. Res., 118, 6165-6174, https://doi.org/10.1002/jgrd.50487.

Evans, J. P., and I. Boyer-Souchet, 2012: Local sea surface temperatures add to extreme precipitation in northeast Australia during La Niña. Geophys. Res. Lett., 39, L10803, https:// doi.org/10.1029/2012GL052014.

Fan, K., Z. Xie, H. Wang, Z. Xu, and J. Liu, 2018: Frequency of spring dust weather in North China linked to sea ice variability in the Barents Sea. Climate Dyn., 51, 4439-4450, https:// doi.org/10.1007/s00382-016-3515-7.

Fujinami, H., and T. Yasunari, 2009: The effects of midlatitude waves over and around the Tibetan Plateau on submonthly variability of the East Asian summer monsoon. Mon. Wea. Rev., 137, 2286-2304, https://doi.org/10.1175/2009MWR2826.1.

Fumière, Q., M. Déqué, O. Nuissier, S. Somot, A. Alias, C. Caillaud, and Y. Seity, 2019: Extreme rainfall in Mediterranean France during the fall: Added value of the CNRM-AROME convectionpermitting regional climate model. Climate Dyn., 55, 77-91, https://doi.org/10.1007/s00382-019-04898-8.

Garcia, R. R., D. R. Marsh, D. E. Kinnison, B. A. Boville, and F. Sassi, 2007: Simulation of secular trends in the middle atmosphere, 1950-2003. J. Geophys. Res., 112, D09301, https:// doi.org/10.1029/2006JD007485.

Giannakaki, P., and O. Martius, 2016: Synoptic-scale flow structures associated with extreme precipitation events in northern Switzerland. Int. J. Climatol., 36, 2497-2515, https://doi.org/ 10.1002/joc. 4508 .

Hersbach, H., and Coauthors, 2020: The ERA5 global reanalysis. Quart. J. Roy. Meteor. Soc., 146, 1999-2049, https://doi.org/ 10.1002/qj.3803.

Hu, Y., P. Zhai, L. Liu, Y. Chen, and Y. Liu, 2015: Dominant large-scale atmospheric circulation systems for the extreme precipitation over the western Sichuan Basin in summer 2013. Adv. Meteor., 2015, 690363, https://doi.org/10.1155/ 2015/690363.

$\mathrm{Hu}, \mathrm{Z}$., C. Zhang, and Q. Hu, 2014: Temperature changes in central Asia from 1979 to 2011 based on multiple datasets. J. Climate, 27, 1143-1167, https://doi.org/10.1175/JCLI-D-13-00064.1.

—, Q. Hu, C. Zhang, X. Chen, and Q. Li, 2016a: Evaluation of reanalysis, spatially interpolated and satellite remotely sensed precipitation data sets in central Asia. J. Geophys. Res., 121, 5648-5663, https://doi.org/10.1002/2016JD024781.

—, Q. Li, X. Chen, Z. Teng, C. Chen, G. Yin, and Y. Zhang, 2016b: Climate changes in temperature and precipitation extremes in an alpine grassland of central Asia. Theor. Appl. Climatol., 126, 519-531, https://doi.org/10.1007/s00704-0151568-x.

—, Q. Zhou, X. Chen, C. Qian, S. Wang, and J. Li, 2017: Variations and changes of annual precipitation in central Asia over the last century. Int. J. Climatol., 37, 157-170, https:// doi.org/10.1002/joc.4988.

Huang, A., Y. Zhou, Y. Zhang, D. Huang, Y. Zhao, and H. Wu, 2014: Changes of the annual precipitation over central Asia in the twenty-first century projected by multimodels of CMIP5. J. Climate, 27, 6627-6646, https://doi.org/10.1175/JCLI-D-1400070.1.

Huang, W., F. H. Chen, S. Feng, J. H. Chen, and X. J. Zhang, 2013: Interannual precipitation variations in the mid-latitude Asia and their association with large-scale atmospheric circulation. 
Chin. Sci. Bull., 58, 3962-3968, https://doi.org/10.1007/s11434013-5970-4.

—_ S. Feng, J. Chen, and F. Chen, 2015: Physical mechanisms of summer precipitation variations in the Tarim Basin in northwestern China. J. Climate, 28, 3579-3591, https://doi.org/ 10.1175/JCLI-D-14-00395.1.

—_, and Coauthors, 2018: A possible mechanism for the occurrence of wintertime extreme precipitation events over South China. Climate Dyn., 52, 2367-2384, https://doi.org/10.1007/ s00382-018-4262-8.

Hurrell, J. W., M. M. Holland, and P. R. Gent, 2013: The Community Earth System Model: A framework for collaborative research. Bull. Amer. Meteor. Soc., 94, 1339-1360, https://doi.org/10.1175/BAMS-D-12-00121.1.

IPCC, 2013: Climate Change 2013: The Physical Science Basis. T. F. Stocker et al., Eds., Cambridge University Press, 1535 pp.

Jiang, J., T. Zhou, X. Chen, and L. Zhang, 2020: Future changes in precipitation over central Asia based on CMIP6 projections. Environ. Res. Lett., 15, 054009, https://doi.org/10.1088/17489326/ab7d03.

Jiang, Z., W. Li, J. Xu, and L. Li, 2015: Extreme precipitation indices over China in CMIP5 models. Part I: Model evaluation. J. Climate, 28, 8603-8619, https://doi.org/10.1175/JCLI-D-150099.1.

Klein Tank, A. M. G., T. C. Peterson, D. A. Quadir, S. Dorji, and X. Zou, 2006: Changes in daily temperature and precipitation extremes in central and South Asia. J. Geophys. Res., 111, D16105, https://doi.org/10.1029/2005JD006316.

Knapp, A. K., and Coauthors, 2008: Consequences of more extreme precipitation regimes for terrestrial ecosystems. BioScience, 58, 811-821, https://doi.org/10.1641/B580908.

Kosaka, Y., S. Xie, and H. Nakamura, 2011: Dynamics of interannual variability in summer precipitation over East Asia. J. Climate, 24, 5435-5453, https://doi.org/10.1175/2011JCLI4099.1.

Krichak, S. O., J. S. Breitgand, S. Gualdi, and S. B. Feldstein, 2014: Teleconnection-extreme precipitation relationships over the Mediterranean region. Theor. Appl. Climatol., 117, 679-692, https://doi.org/10.1007/s00704-013-1036-4.

Kug, J.-S., B. P. Kirtman, and I.-S. Kang, 2006: Interactive feedback between ENSO and the Indian Ocean in an interactive ensemble coupled model. J. Climate, 19, 6371-6381, https:// doi.org/10.1175/JCLI3980.1.

Kumar, K. N., A. Molini, T. B. M. J. Ouarda, and M. N. Rajeevan, 2017: North Atlantic controls on wintertime warm extremes and aridification trends in the Middle East. Sci. Rep., 7, 12301, https://doi.org/10.1038/s41598-017-12430-3.

Kunkel, K. E., 2003: North American trends in extreme precipitation. Nat. Hazards, 29, 291-305, https://doi.org/10.1023/A: 1023694115864.

Li, H., H. Chen, H. Wang, J. Sun, and J. Ma, 2018: Can Barents Sea ice decline in spring enhance summer hot drought events over northeastern China? J. Climate, 31, 4705-4725, https://doi.org/ 10.1175/JCLI-D-17-0429.1.

—, S. He, Y. Gao, H. Chen, and H. Wang, 2020: North Atlantic modulation of interdecadal variations in hot drought events over northeastern China. J. Climate, 33, 4315-4332, https:// doi.org/10.1175/JCLI-D-19-0440.1.

Li, J., F. Zheng, C. Sun, J. Feng, and J. Wang, 2019: Pathways of influence of the Northern Hemisphere mid-high latitudes on East Asian climate: A review. Adv. Atmos. Sci., 36, 902-921, https://doi:10.1007/s00376-019-8236-5.

Li, Z., Y. Chen, W. Li, H. Deng, and G. Fang, 2015: Potential impacts of climate change on vegetation dynamics in central
Asia. J. Geophys. Res., 120, 12345-12 356, https://doi.org/ 10.1002/2015JD023618.

Lim, Y. K., 2015: The East Atlantic/West Russia (EA/WR) teleconnection in the North Atlantic: Climate impact and relation to Rossby wave propagation. Climate Dyn., 44, 3211-3222, https://doi.org/10.1007/s00382-014-2381-4.

Lioubimtseva, E., and C. M. Henebry, 2009: Climate and environmental change in arid Central Asia: Impacts, vulnerability, and adaptations. J. Arid Environ., 73, 963-977, https://doi.org/ 10.1016/j.jaridenv.2009.04.022.

Liu, H., X. Liu, and B. Dong, 2017: Intraseasonal variability of winter precipitation over central Asia and the western Tibetan Plateau from 1979 to 2013 and its relationship with the North Atlantic Oscillation. Dyn. Atmos. Oceans, 79, 31-42, https:// doi.org/10.1016/j.dynatmoce.2017.07.001.

Liu, Y., P. Zhai, L. Hu, and Y. Chen, 2015: Dominant large-scale atmospheric circulation systems for the extreme precipitation over the western Sichuan Basin in summer 2013. Adv. Meteor., 2015, 690363, https://doi.org/10.1155/2015/690363.

Lorenz, E. N., 1956: Empirical orthogonal functions and statistical weather prediction. MIT Department of Meteorology Statistical Forecast Project Tech. Rep. 1, 49 pp.

Lu, R., Z. Zhu, T. Li, and H. Zhang, 2020: Interannual and interdecadal variabilities of spring rainfall over Northeast China and their associated sea surface temperature anomaly forcings. J. Climate, 33, 1423-1435, https://doi.org/10.1175/ JCLI-D-19-0302.1.

Ma, Q., J. Zhang, A. T. Game, Y. Chang, and S. Li, 2020: Spatiotemporal variability of summer precipitation and precipitation extremes and associated large-scale mechanisms in Central Asia during 1979-2018.J. Hydrol. X, 8, 100061, https:// doi.org/10.1016/j.hydroa.2020.100061.

Madsen, H., D. Lawrence, M. Lang, M. Martinkova, and T. Kjeldsen, 2014: Review of trend analysis and climate change projections of extreme precipitation and floods in Europe. J. Hydrol., 519, 3634-3650, https://doi.org/10.1016/j.jhydrol.2014.11.003.

Malsy, M., T. A. D. Beek, and M. Floerke, 2015: Evaluation of large-scale precipitation data sets for water resources modelling in Central Asia. Environ. Earth Sci., 73, 787-799, https:// doi.org/10.1007/s12665-014-3107-y.

Mathis, M., P. Sorrel, S. Klotz, X. Huang, and H. Oberhänsli, 2014: Regional vegetation patterns at Lake Son Kul reveal Holocene climatic variability in central Tien Shan (Kyrgyzstan, Central Asia). Quat. Sci. Rev., 89, 169-185, https://doi.org/ 10.1016/j.quascirev.2014.01.023.

Miao, R., M. Wen, R. Zhang, and L. Li, 2019: The influence of wave trains in mid-high latitudes on persistent heavy rain during the first rainy season over South China. Climate Dyn., 53, 2949-2968, https://doi.org/10.1007/s00382-019-04670-y.

Murakami, M., 1979: Large-scale aspects of deep convective activity over the GATE area. Mon. Wea. Rev., 107, 994-1013, https:// doi.org/10.1175/1520-0493(1979)107<0994:LSAODC>2.0.CO;2.

Nakamura, H., T. Izumi, and T. Sampe, 2002: Interannual and decadal modulations recently observed in the Pacific storm track activity and East Asian winter monsoon. J. Climate, 15, 1855-1874, https://doi.org/10.1175/1520-0442(2002)015<1855: IADMRO $>2.0 . \mathrm{CO} ; 2$.

North, G. R., T. L. Bell, R. F. Cahalan, and F. J. Moeng, 1982: Sampling errors in the estimation of empirical orthogonal functions. Mon. Wea. Rev., 110, 699-706, https://doi.org/ 10.1175/1520-0493(1982)110<0699:SEITEO > 2.0.CO;2.

Omondi, P. A., and Coauthors, 2014: Changes in temperature and precipitation extremes over the Greater Horn of Africa region 
from 1961 to 2010. Int. J. Climatol., 34, 1262-1277, https:// doi.org/10.1002/joc.3763.

Orlowsky, B., and S. Seneviratne, 2012: Global changes in extreme events: Regional and seasonal dimension. Climatic Change, 110, 669-696, https://doi.org/10.1007/s10584-011-0122-9.

Park, J. S., J. G. Jhun, and E. J. Lee, 2009: Characteristic large-scale circulation anomalies associated with persistent features of extreme precipitation over northeast Asia from premonsoon season to monsoon season. J. Geophys. Res., 114, D11108, https://doi.org/10.1029/2008JD011031.

Peng, D., and T. Zhou, 2017: Why was the arid and semiarid northwest China getting wetter in the recent decades? J. Geophys. Res., 122, 9060-9075, https://doi.org/10.1002/2016JD026424.

Prakash, S., R. M. Gairola, and A. K. Mitra, 2015: Comparison of large-scale global land precipitation from multisatellite and reanalysis products with gauge-based GPCC data sets. Theor. Appl. Climatol., 121, 303-317, https://doi.org/10.1007/s00704014-1245-5.

Prein, A. F., R. M. Rasmussen, and K. Ikeda, 2016: The future intensification of hourly precipitation extremes. Nat. Climate Change, 7, 48-52, https://doi.org/10.1038/nclimate3168.

Queralt, S., E. Hernandez, D. Barriopedro, D. Gallego, P. Ribera, and C. Casanova, 2009: North Atlantic Oscillation influence and weather types associated with winter total and extreme precipitation events in Spain. Atmos. Res., 94, 675-683, https:// doi.org/10.1016/j.atmosres.2009.09.005.

Rayner, N. A., D. E. Parker, E. B. Horton, C. K. Folland, L. V. Alexander, D. P. Rowell, E. C. Kent, and A. Kaplan, 2003: Global analyses of sea surface temperature, sea ice, and night marine air temperature since the late nineteenth century. J. Geophys. Res., 108, 4407, https://doi.org/10.1029/2002JD002670.

Ren, X., X. Yang, T. Zhou, and J. Fang, 2011: Diagnostic comparison of wintertime East Asian subtropical jet and polar-front jet: Large-scale characteristics and transient eddy activities. Acta Meteor. Sin., 25, 21-33, https://doi.org/10.1007/ s13351-011-0002-2.

Revadekar, J. V., and B. Preethi, 2011: Statistical analysis of the relationship between summer monsoon precipitation extremes and foodgrain yield over India. Int. J. Climatol., 32, 419-429, https://doi.org/10.1002/joc.2282.

Schiemann, R., D. Lüthi, P. L. Vidale, and C. Schaer, 2008: The precipitation climate of Central Asia-Intercomparison of observational and numerical data sources in a remote semiarid region. Int. J. Climatol., 28, 295-314, https://doi.org/ 10.1002/joc. 1532 .

Schlesinger, M. E., and N. Ramankutty, 1994: An oscillation in the global climate system of period 65-70 years. Nature, $\mathbf{3 6 7}$, 723-726, https://doi.org/10.1038/367723a0.

Sha, Y., and Coauthors, 2018: Role of the Tian Shan Mountains and Pamir Plateau in increasing spatiotemporal differentiation of precipitation over interior Asia. J. Climate, 31, 8141-8162, https://doi.org/10.1175/JCLI-D-17-0594.1.

Silva, V. B. S., V. E. Kousky, and R. W. Higgins, 2011: Daily precipitation statistics for South America: An intercomparison between NCEP reanalyses and observations. J. Hydrometeor., 12, 101-117, https://doi.org/10.1175/2010JHM1303.1.

Sun, G., and Coauthors, 2020: Analysis of local land-atmosphere coupling in rainy season over a typical underlying surface in Tibetan Plateau based on field measurements and ERA5. Atmos. Res., 243, 105025, https://doi.org/10.1016/ j.atmosres.2020.105025.

Takaya, K., and H. Nakamura, 2001: A formulation of a phase independent wave-activity flux for stationary and migratory quasigeostrophic eddies on a zonally varying basic flow. J. Atmos. Sci., 58, 608-627, https://doi.org/10.1175/15200469(2001)058<0608:AFOAPI > 2.0.CO;2.

Trenberth, K. E., 1991: Climate diagnostics from global analyses: Conservation of mass in ECMWF analyses. J. Climate, 4, 707-722, https://doi.org/10.1175/1520-0442(1991)004<0707: CDFGAC $>2.0 . \mathrm{CO} ; 2$.

Varis, O., 2014: Resources: Curb vast water use in central Asia. Nature, 514, 27-29, https://doi.org/10.1038/514027a.

Wang, C., 2019: Three-ocean interactions and climate variability: A review and perspective. Climate Dyn., 53, 5119-5136, https:// doi.org/10.1007/s00382-019-04930-x.

Wang, H., and Coauthors, 2020: The belt and road region climate change: Facts, impacts and possible risks (in Chinese). Trans. Atmos. Sci., 43, 1-9.

Wang, L., Y. Qian, Y. Zhang, C. Zhao, L. R. Leung, A. Huang, and C. Xiao, 2016: Observed variability of summer precipitation pattern and extreme events in East China associated with variations of the East Asian summer monsoon. Int. J. Climatol., 36, 2942-2957, https://doi.org/10.1002/joc.4530.

Wang, S., M. Zhang, M. Sun, B. Wang, and X. Li, 2013: Changes in precipitation extremes in alpine areas of the Chinese Tianshan Mountains, central Asia, 1961-2011. Quat. Int., 311, 97-107, https://doi.org/10.1016/j.quaint.2013.07.008.

_- F. Jiang, and Y. Ding, 2015: Spatial coherence of variations in seasonal extreme precipitation events over Northwest Arid Region, China. Int. J. Climatol., 35, 4642-4654, https://doi.org/ 10.1002/joc. 4313 .

Wang, X., H. Huang, and Z. Huang, 2011: The causation analysis of persistent heavy rain over southern China during May-June 2010. Meteor. Mon., 37, 1206-1215, https://doi.org/10.7519/ j.issn.1000-0526.2011.10.003.

Wen, M., S. Yang, A. Kumar, and P. Zhang, 2009: An analysis of the large-scale climate anomalies associated with the snowstorms affecting China in January 2008. Mon. Wea. Rev., 137, 1111-1131, https://doi.org/10.1175/2008MWR2638.1.

Wilks, D., 2006: Principal component (EOF) analysis. Statistical Methods in the Atmospheric Sciences, 2nd ed. Elsevier, 463-508.

Wolff, C., B. Plessen, A. S. Dudashvilli, S. F. M. Breitenbach, H. Cheng, L. R. Edwards, and M. R. Strecker, 2017: Precipitation evolution of Central Asia during the last 5000 years. Holocene, 27, 142-154, https://doi.org/10.1177/0959683616652711.

Wu, C., and G. Huang, 2015: Changes in heavy precipitation and floods in the upstream of the Beijiang River basin. South China. Int. J. Climatol., 35, 2978-2992, https://doi.org/10.1002/joc.4187.

Wu, G., 2001: Comparison between the complete form vorticity equation and the traditional vorticity equation. Acta Meteor. Sin., 59, 385-392.

Wu, X., S. Guo, J. Yin, G. Yang, Y. Zhong, and D. Liu, 2018: On the event-based extreme precipitation across China: Time distribution patterns, trends, and return levels. J. Hydrol., 562, 305-317, https://doi.org/10.1016/j.jhydrol.2018.05.028.

Xie, P., M. Chen, S. Yang, A. Yatagai, T. Hayasaka, Y. Fukushima, and C. Liu, 2007: A gauge-based analysis of daily precipitation over East Asia. J. Hydrometeor., 8, 607-626, https://doi.org/ 10.1175/JHM583.1.

Xue, T., G. Tang, L. Sun, Y. Wu, Y. Liu, and Y. Dou, 2017: Longterm trends in precipitation and precipitation extremes and underlying mechanisms in the U.S. Great Basin during 19512013. J. Geophys. Res., 122, 6152-6169, https://doi.org/10.1002/ 2017JD026682.

Yang, L., 2007: Anomalous perturbation kinetic energy of Rossby wave along East Asian westerly jet and its association with 
summer rainfall in China. Chin. J. Atmos. Sci., 31, 586-595, http://doi.org/10.3878/j.issn.1006-9895.2007.04.04.

Yin, Z. Y., H. Wang, and X. Liu, 2014: A comparative study on precipitation climatology and interannual variability in the lower midlatitude East Asia and central Asia. J. Climate, 27, 7830-7848, https://doi.org/10.1175/JCLI-D14-00052.1.

Zhang, J., H. Chen, and S. Zhao, 2019: A tripole pattern of summertime rainfall and the teleconnections linking northern China to the Indian subcontinent. J. Climate, 32, 3637-3653, https://doi.org/10.1175/JCLI-D-18-0659.1.

—, Z. Chen, H. Chen, Q. Ma, and T. Asaminew, 2020: North Atlantic multidecadal variability enhancing decadal extratropical extremes in boreal late summer in the early $21 \mathrm{st}$ century. J. Climate, 33, 6047-6064, https://doi.org/10.1175/ JCLI-D-19-0536.1.

Zhang, M., Y. Chen, Y. Shen, and Y. Li, 2017: Changes of precipitation extremes in arid central Asia. Quat. Int., 436, 16-27, https://doi.org/10.1016/j.quaint.2016.12.024. and B. Li, 2019: Tracking climate change in Central Asia through temperature and precipitation extremes. J. Geogr. Sci., 29, 3-28, https://doi.org/10.1007/s11442-019-1581-6.

-, H. Yu, D. K. Andrew, Y. Wei, J. Huang, and Y. Ren, 2020: Greater probability of extreme precipitation under $1.5^{\circ} \mathrm{C}$ and $2^{\circ} \mathrm{C}$ warming limits over East-Central Asia. Climatic Change, 162, 603-619, https://doi.org/10.1007/s10584-020-02725-2.

Zhang, Q., V. P. Singh, J. Li, F. Jiang, and Y. Bai, 2012: Spatiotemporal variations of precipitation extremes in Xinjiang, China. J. Hydrol., 434-435, 7-18, https://doi.org/10.1016/ j.jhydrol.2012.02.038.

Zhao, Y., and Coauthors, 2014: Impact of the middle and upper tropospheric cooling over central Asia on the summer rainfall in the Tarim Basin, China. J. Climate, 27, 4721-4732, https:// doi.org/10.1175/JCLI-D-13-00456.1.

Zhong, Y. B., and Coauthors, 2017: On the teleconnection patterns to precipitation in the eastern Tianshan Mountains, China. Climate Dyn., 49, 3123-3139, https://doi.org/10.1007/s00382016-3500-1. 